OPEN ACCESS

Edited by:

John D. Imig,

Medical College of Wisconsin, USA

Reviewed by:

Vladimir V. Matchkov,

University of Aarhus, Denmark

Shuangtao Ma

University of Texas Health Science

Center at Houston, USA

${ }^{*}$ Correspondence:

Nadia Ayala-Lopez

nadia.ayala.lopez@gmail.com

Specialty section: This article was submitted to

Vascular Physiology,

a section of the journal

Frontiers in Physiology

Received: 25 October 2016

Accepted: 13 January 2017

Published: 08 February 2017

Citation:

Ayala-Lopez N, Thompson JM and Watts SW (2017) Perivascular

Adipose Tissue's Impact on

Norepinephrine-Induced Contraction of Mesenteric Resistance Arteries.

Front. Physiol. 8:37.

doi: 10.3389/fphys.2017.00037

\section{Perivascular Adipose Tissue's Impact on Norepinephrine-Induced Contraction of Mesenteric Resistance Arteries}

\author{
Nadia Ayala-Lopez *, Janice M. Thompson and Stephanie W. Watts \\ Department of Pharmacology and Toxicology, Michigan State University, East Lansing, MI, USA
}

Background: Perivascular adipose tissue (PVAT) can decrease vascular contraction to NE. We tested the hypothesis that metabolism and/or uptake of vasoactive amines by mesenteric PVAT (MPVAT) could affect NE-induced contraction of the mesenteric resistance arteries.

Methods: Mesenteric resistance vessels (MRV) and MPVAT from male Sprague-Dawley rats were used. RT-PCR and Western blots were performed to detect amine metabolizing enzymes. The Amplex ${ }^{\circledR}$ Red Assay was used to quantify oxidase activity by detecting the oxidase reaction product $\mathrm{H}_{2} \mathrm{O}_{2}$ and the contribution of PVAT on the mesenteric arteries' contraction to NE was measured by myography.

Results: Semicarbazide sensitive amine oxidase (SSAO) and monoamine oxidase A (MAO-A) were detected in MRV and MPVAT by Western blot. Addition of the amine oxidase substrates tyramine or benzylamine $(1 \mathrm{mM})$ resulted in higher amine oxidase activity in the MRV, MPVAT, MPVAT's adipocyte fraction (AF), and the stromal vascular fraction (SVF). Inhibiting SSAO with semicarbazide (1 $\mathrm{mM})$ decreased amine oxidase activity in the MPVAT and AF. Benzylamine-driven, but not tyramine-driven, oxidase activity in the MRV was reduced by semicarbazide. By contrast, no reduction in oxidase activity in all sample types was observed with use of the monoamine oxidase inhibitors clorgyline $(1 \mu \mathrm{M})$ or pargyline $(1 \mu \mathrm{M})$. Inhibition of MAO-A/B or SSAO individually did not alter contraction to NE. However, inhibition of both MAO and SSAO increased the potency of NE at mesenteric arteries with PVAT. Addition of MAO and SSAO inhibitors along with the $\mathrm{H}_{2} \mathrm{O}_{2}$ scavenger catalase reduced PVAT's anti-contractile effect to NE. Inhibition of the norepinephrine transporter (NET) with nisoxetine also reduced PVAT's anti-contractile effect to NE.

Conclusions: PVAT's uptake and metabolism of NE may contribute to the anti-contractile effect of PVAT. MPVAT and adipocytes within MPVAT are a source of SSAO.

Keywords: norepinephrine, monoamine oxidase, semicarbazide sensitive amine oxidase, amine oxidase (coppercontaining), isometric contraction, uptake transporters, norepinephrine transporter, organic cation transporter 


\section{INTRODUCTION}

Perivascular adipose tissue (PVAT) makes up the fourth layer of most blood vessels (Chaldakov et al., 2007). PVAT is appreciated for its effects on the vasculature, from mediating relaxation (Brandes, 2007; Fesus et al., 2007) to stimulating contraction of arteries by the release of catecholamines (Gao et al., 2006; Ayala-Lopez et al., 2014). Increased visceral fat, which includes mesenteric fat, is associated with increased cardiovascular risk (Kotchen, 2010). Thus, our focus is on the mesenteric PVAT because it surrounds resistance arteries, which provide increased vascular resistance in hypertension (for a review: Intengan and Schiffrin, 2000). Investigating mesenteric PVAT's mechanisms of handling NE, the sympathetic neurotransmitter, is relevant in understand the pathology in this disease because sympathetic nervous system activity is increased in obesityrelated hypertension (Hall et al., 2010).

In normal (non-disease) animal models, PVAT inhibits contraction of the underlying arteries to several agonists, including norepinephrine (NE) (Soltis and Cassis, 1991; Löhn et al., 2002) in a mechanism dependent on transport-dependent uptake of NE. Mesenteric and aortic PVAT can take up NE applied exogenously, which could contribute to PVAT's anticontractile effect on mesenteric and aortic arteries exposed to NE (Ayala-Lopez et al., 2015). Nerve terminals terminate NE activation of post-synaptic receptors through uptake of NE followed by storage into vesicles and/or by degradation by NE metabolizing enzymes. Like nerves, PVAT also has a storage of catecholamines (Ayala-Lopez et al., 2014) but whether degradation of NE occurs within PVAT has not been investigated.

PVAT affects arterial contraction through an adrenergic system that is complete with the release and uptake of NE (Ayala-Lopez et al., 2014, 2015). We hypothesize that PVAT's anti-contractile effect is through its amine metabolizing activity in addition to NE uptake. The NE metabolizing enzymes monoamine oxidases $\mathrm{A}(\mathrm{MAO}-\mathrm{A})$ and monoamine oxidase $\mathrm{B}$ (MAO-B) are present in human white adipose tissue adipocytes isolated from mammary and abdominal lipectomies (Pizzinat et al., 1999). One study supports the presence in adipose tissue (canine subcutaneous) of catechol-o-methyl transferase (COMT), another metabolizer of NE (Belfrage et al., 1977). Lastly, the dual function enzyme, semicarbazide sensitive amine oxidase (SSAO), also known as vascular adhesion protein-1 (VAP-1) for its role as a leukocyte adhesion molecule, catalyzes the deamination of amines. SSAO is shed from the plasma membrane of adipocytes. Circulating levels of SSAO are elevated in cardiovascular disease (Abella et al., 2004) and atherosclerosis (Karadi et al., 2002) making SSAO in PVAT an interesting target of study. NE is a substrate for SSAO in rat brown adipose tissue (Barrand and Callingham, 1982). The presence of and the effect

Abbreviations: 5-HT, 5-hydroxytryptamine; AF, adipocyte fraction; COMT, catechol-o-methyl-transferase; DMSO, dimethyl sulfoxide; MAO, monoamine oxidase; MPVAT, mesenteric perivascular adipose tissue; MRV, mesenteric resistance vessels; NE, norepinephrine; NET, norepinephrine transporter; OCT3, organic cation transporter 3; PVAT, perivascular adipose tissue; SVF, stromal vascular fraction; SSAO, semicarbazide sensitive amine oxidase; WAT, white adipose tissue. that amine metabolism in PVAT on vascular contraction to NE is not known.

To study NE handling in PVAT, we used mesenteric resistance arteries with and without PVAT. Additionally, PVAT was separated into its fractional components, the adipocyte fraction (AF) and the stromal vascular fraction (SVF). The stromal vascular fraction is the non-buoyant fraction separated from PVAT. It contains fibroblasts, mesenchymal stem cells, lymphocytes, macrophages and endothelial cells (Szasz et al., 2013). Gene expression analysis and Western blots helped to identify which NE metabolizing enzymes are present in mesenteric resistance vessels (MRV- pooled mesenteric resistance arteries and veins) and in their surrounding MPVAT. We measured oxidase activity after the addition of tyramine or benzylamine, substrates of MAO and SSAO (Visentin et al., 2005) and used pharmacological inhibitors of amine oxidases to determine which oxidases are important for the activity observed. Contraction to NE was recorded in isolated third-order mesenteric arteries with and without PVAT exposed to inhibitors of MAO-A/B, SSAO and NE transporters. Our work presents insight into the impact of PVAT on arterial contraction to NE.

\section{MATERIALS AND METHODS}

\section{Chemicals}

Norepinephrine hydrochloride, nisoxetine hydrochloride, semicarbazide hydrochloride, and catalase were purchased from Sigma-Aldrich (St. Louis, MO). Pargyline hydrochloride for the contractility experiments was purchased from Cayman Chemical (Ann Arbor, MI). Corticosterone was purchased from Tocris Bioscience (United Kingdom). Pargyline and clorgyline used in the oxidase assay experiments were supplied within the Amplex ${ }^{\circledR}$ Red Monoamine Oxidase Assay Kit (cat\# A12214, ThermoFisher Scientific, Grand Island, NY USA).

\section{Animals}

Male Sprague-Dawley rats (225-275g or $\sim 8-10$ weeks of age, Charles River, Indianapolis, IN USA) were used. All protocols were approved by the MSU Institutional Animal Care and Use Committee and follow the "Guide for the Care and Use of Laboratory Animals," 8th edition, 2011. Rats were anesthetized with sodium pentobarbital $(60-80 \mathrm{mg} / \mathrm{kg}$, IP). Anesthesia was verified by lack of paw pinch and eye blink reflexes. Death was assured by pneumothorax and exsanguination after which tissues were removed for one of the following protocols.

\section{Tissue Dissection}

The liver was collected, snap frozen in liquid $\mathrm{N}_{2}$ and saved to serve as a positive control for the RT-PCR and Western blot assays. Mesentery, brain and aorta were collected in physiological salt solution (PSS); in mM; $130 \mathrm{NaCl} ; 4.7 \mathrm{KCl} ; 1.18 \mathrm{KH}_{2} \mathrm{PO}_{4}$; $1.17 \mathrm{MgSO}_{4} 7 \mathrm{H}_{2} \mathrm{O} ; 14.8 \mathrm{NaHCO}_{3} ; 5.5$ dextrose; $0.03 \mathrm{CaNa}_{2}$ ethylenediaminetetraacetic acid; $1.6 \mathrm{CaCl}_{2}$ ( $\mathrm{pH} 7.2$ ). A portion the rat brain corresponding to the midbrain and pons was dissected and the aorta was cleaned of PVAT. Both samples were then saved in potassium phosphate buffer $(50 \mathrm{mM})$ for the oxidase activity assay. The same tissues (brain and aorta without 
PVAT) from a separate set of animals were dissected, frozen in liquid $\mathrm{N}_{2}$ and saved for RT-PCR. MPVAT and the associated mesenteric resistance arteries and veins (MRV) were separated out in a Sylgard ${ }^{\circledR}$ coated petri dish in PSS with the aid of a stereomicroscope. The MPVAT was either used for fractionation, frozen in liquid $\mathrm{N}_{2}$ for protein isolation, or saved in potassium phosphate buffer $(50 \mathrm{mM})$ for the oxidase assay. The MRV were either frozen in liquid $\mathrm{N}_{2}$ for protein or RNA isolation, or saved in potassium phosphate buffer $(50 \mathrm{mM})$. Samples for the oxidase activity assays were saved at $-20^{\circ} \mathrm{C}$ and used within 1 week. Mesenteric resistance arteries (2 $\mathrm{mm}$ in length) with or without PVAT for the use in isometric contraction experiments were dissected out in a Sylgard ${ }^{\circledR}$ coated petri dish in PSS with the aid of a stereomicroscope.

\section{Adipocyte and SVF Isolation}

MPVAT was added to $1 \mathrm{~mL}$ of PSS with $1 \mathrm{mg} / \mathrm{mL}$ collagenase from Clostridium histolyticum type IA (cat\# C9891, Sigma) and incubated at $37^{\circ} \mathrm{C}$ with gentle agitation until fully digested. The sample was centrifuged at $200 \times \mathrm{g}$ for $5 \mathrm{~min}$ after which the SVF was transferred into a separate tube. The fractions were then washed six times by adding $1 \mathrm{~mL}$ of PSS and centrifuging at $200 \times \mathrm{g}$ for $10 \mathrm{~min}$. This protocol is one used to routinely isolate adipocytes and that has been verified by other groups to satisfactorily exclude other cell types (Vargovic et al., 2013). Purity of the isolation (>95\% adipocytes) was verified by counting the adipocytes vs. non-adipocytes present with a hemocytometer. Phase contrast images of the fractions were taken with a $20 \times$ objective (Hi PLAN I 20X/ 0.30 PH1) on an inverted microscope DMil (Leica, Buffalo Grove, IL, USA) using Leica Application Suite (LAS). The PSS was then removed and the samples were placed in $50 \mathrm{mM}$ potassium phosphate buffer to be used in the oxidase assay before freezing or snap frozen in liquid $\mathrm{N}_{2}$ for protein isolation.

\section{Real-Time PCR}

All tissues (brain, liver, MRV, MPVAT, and aorta) were homogenized using the Bead Ruptor 24 (Omni International, NW Kennesaw, GA). RNA was extracted with the Quick RNA MiniPrep kit (cat\# R1054, Zymo Research Corporation, Irving, CA USA) and purity (260/280 and 260/230 ratios $\geq$ 1.8) was verified using a Nanodrop 2000C spectrophotometer (Thermo Scientific, Wilmington, DE USA). The mRNA (1 $\mu \mathrm{g})$ was reverse transcribed with the High-Capacity cDNA Reverse Transcription Kit (cat\# 4368814, ThermoFisher Scientific). RT-PCR was performed using PerfeCTa FastMix II, ROX (cat\# 95119, Quanta Biosciences, Gaithersburg, MD USA) on the ABI 7500 Fast Real Time PCR system (Life Technologies, Carlsbad, CA USA) with the following parameters: $95^{\circ} \mathrm{C}$ for $20 \mathrm{~s}, 95^{\circ} \mathrm{C}$ for $1 \mathrm{~s}$ and $60^{\circ} \mathrm{C}$ for $20 \mathrm{~s}$ for 40 cycles. Taqman Primers were purchased from ThermoFisher Scientific. The sequences are proprietary. Thus, we have listed the catalog numbers which are as follows: Aoc3 (cat\# 4448892, assay ID: Rn01452826_m1), Comt (cat\#4448892, assay ID: Rn01404927_g1: Actb (cat\#4448892, assay ID: Rn00667869_m1), Maoa (cat\#4448892, assay ID: Rn01430950_m1), Maob (cat\#4448892, assay ID: Rn00566203_m1). Measures were

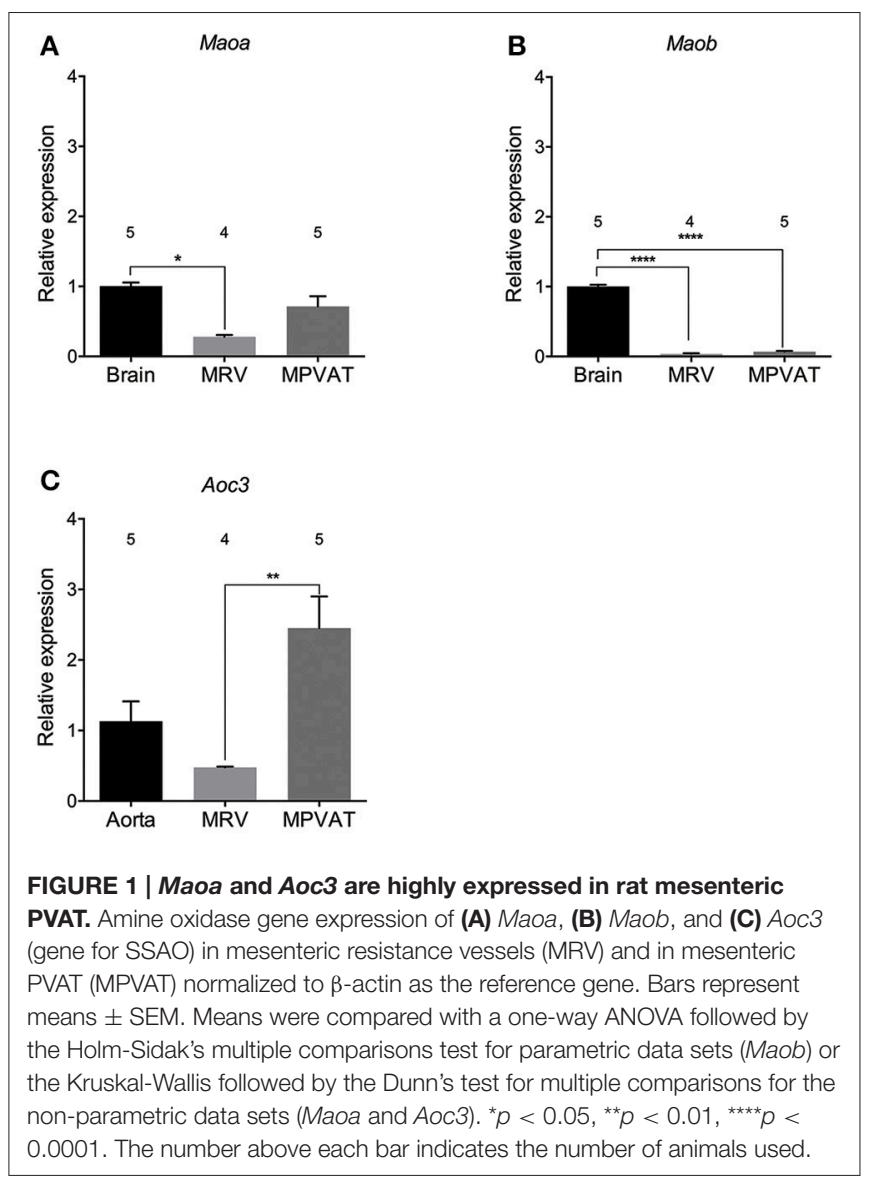

normalized to $\beta$-actin $(A c t b)$ and expressed as fold change relative to the positive control tissue as described by Livak and Schmittgen (2001).

\section{Western Blots}

MPVAT and MRV protein was isolated in phosphate buffered saline (PBS) with protease inhibitors [sodium orthovanadate $(1 \mathrm{mM})$, aprotinin/leupeptin $(100 \mu \mathrm{g} / \mathrm{ml})$ and phenylmethylsulfonyl fluoride $(1 \mathrm{mM})]$ and homogenized using the Bead Ruptor 24 (Omni International). The protein from the positive controls was isolated as follows. Stomach fundus and gut mucosa were dissected from the rat and were placed into RIPA buffer (cat\# R3792, Teknova, Hollister, CA) with the above protease inhibitors before homogenizing with the Bead Ruptor 24 (Omni International) and centrifuging at 10,000 $\mathrm{rpm}$ for $10 \mathrm{~min}$. Protein from the aorta was isolated in $1 \mathrm{X}$ lysis buffer [Tris $\mathrm{HCl}(62.5 \mathrm{mM}) \mathrm{pH} 7.8,2 \%$ SDS, $10 \%$ glycerol] with the above protease inhibitors, frozen in liquid $\mathrm{N}_{2}$, homogenized with mortar and pestle followed by a centrifugation at 11,000 rpm for $10 \mathrm{~min}$. Supernatants were then separated. The Jurkat whole cell lysate was purchased from Santa Cruz Biotechnology (cat\# SC-2204, Dallas, TX). The protein concentrations were determined using the Bicinchoninic Acid Protein Assay Kit (cat\# BCA1, Sigma-Aldrich). The protein samples (50 $\mu \mathrm{g})$ were separated on $10 \%$ SDS polyacrylamide gels using the Bio-Rad Mini Protean 3 system. Protein was transferred to PVDF-FL 


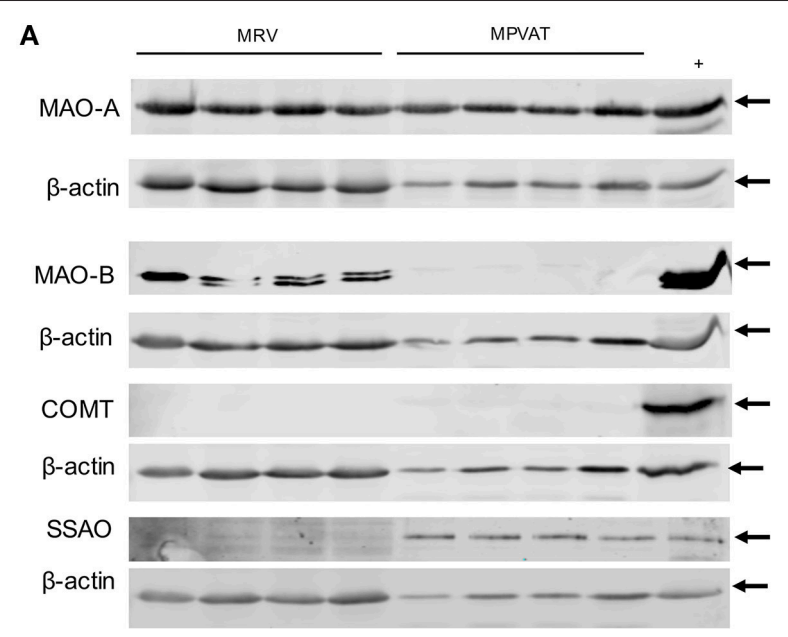

B

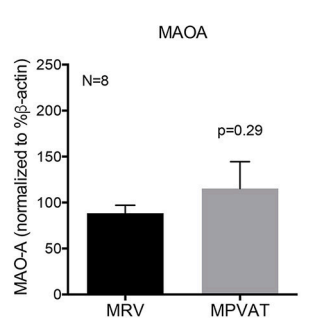

D

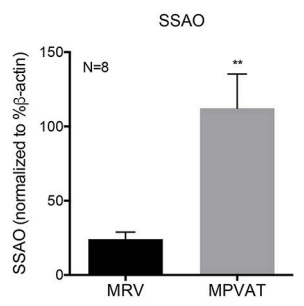

C

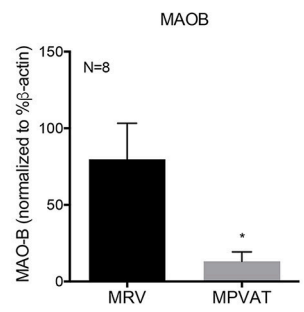

FIGURE 2 | MAO-A, MAO-B, and SSAO but not COMT are present in rat MRV and MPVAT. (A) Western blot analysis of monoamine metabolism enzymes MAO-A, MAO-B, COMT, and SSAO in mesenteric resistance vessels (MRV) and in mesenteric PVAT (MPVAT) from eight animals. Positive controls were gut mucosa for MAO-A, stomach fundus for MAO-B, Jurkat cells for COMT and aorta for SSAO. Densitometry analysis of Western blot bands for (B) MAO-A, (C) MAO-B, (D) SSAO. Bars represent the means \pm SEM. Western blot densitometry was statistically analyzed with a paired Student's $t$-test. ${ }^{*} p<0.05,{ }^{* *} p<0.01$.

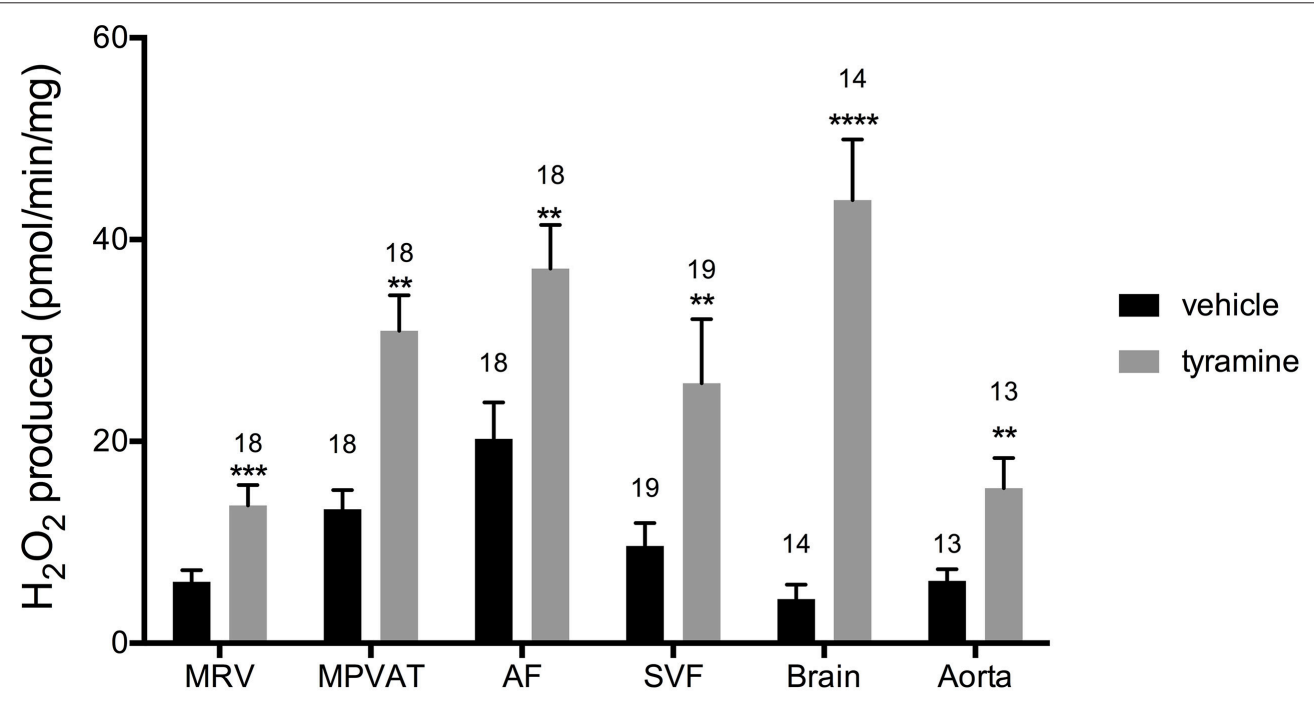

FIGURE 3 | Tyramine drives amine oxidase activity in the MRV, MPVAT, AF, and SVF. Tyramine, a substrate for amine oxidases, increased the oxidase activity in the mesenteric resistance vessels (MRV), mesenteric PVAT (MPVAT), adipocyte fraction (AF), and the stromal-vascular fraction (SVF). The brain and aorta were also tested as positive controls. Bars represent the means \pm SEM for the number of animals indicated above each bar. Means were compared by a Mann-Whitney test. ${ }^{* *} p<0.01,{ }^{* * *} p<0.001,{ }^{* * * *} p<0.0001$ vs. control of that same sample type.

(MAO-A) or nitrocellulose (MAO-B, COMT, VAP-1) and blocked for $3 \mathrm{~h}$ at $4^{\circ} \mathrm{C}$ in $4 \%$ chicken egg ovalbumin (MAO-A, $\beta$-actin), LI-COR Odyssey Blocking Buffer (MAO-B, COMT) or $5 \%$ bovine serum albumin (VAP-1). Primary antibody [MAO-A, 1:200 (epitope corresponds to amino acids 458-527 of MAO-A of human origin; Santa Cruz Biotechnology, cat\#SC-20156); MAO$\mathrm{B}, 1: 200$ (epitope near the C-terminus of MAO-B of human origin; Santa Cruz Biotechnology, cat\#SC-18401); COMT, 1:200 (epitope corresponding to amino acids 1-271 of COMT of human origin; Santa Cruz Biotechnology, cat\#SC-25844); VAP1, 1:200 (epitope near the C-terminus of VAP-1 of human origin; Santa Cruz Biotechnology, cat\#SC-13741); or $\beta$-actin, 1:2000 (Sigma, cat\#A3854)] was incubated overnight in blocking buffer at $4^{\circ} \mathrm{C}$. Antibody was recovered and blots were washed with TBS $+0.1 \%$ Tween 20 (TBS- $\mathrm{T}$ ) for $10 \mathrm{~min}$ at $4^{\circ} \mathrm{C}$ (three times). Blots were then incubated with species-specific LI-COR IRDye 800 
A

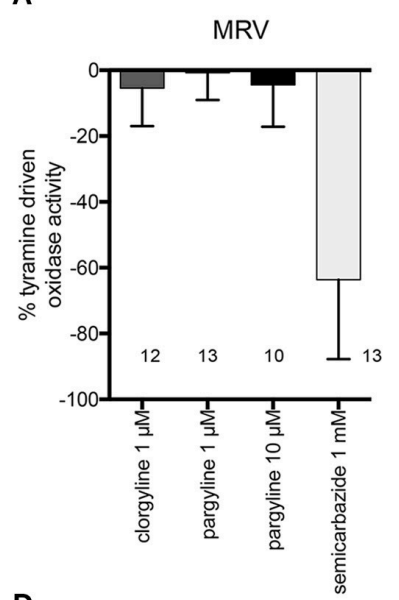

D

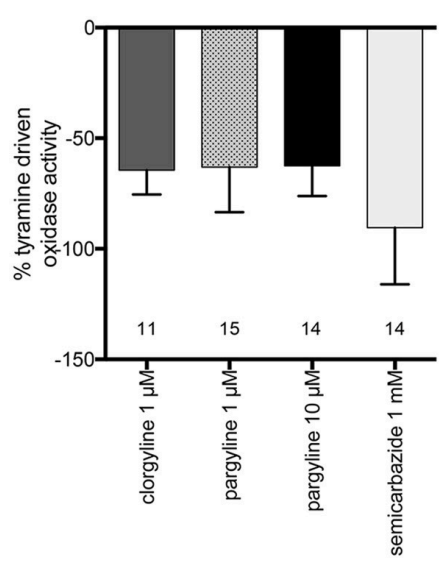

B

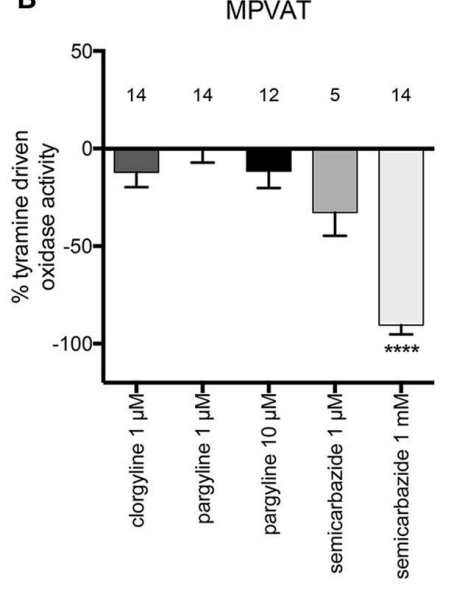

E

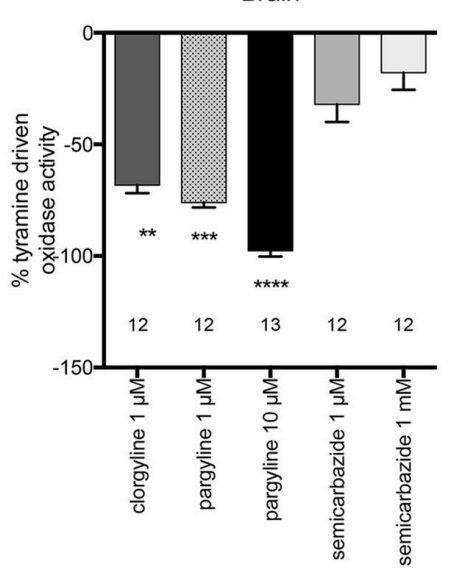

C AF

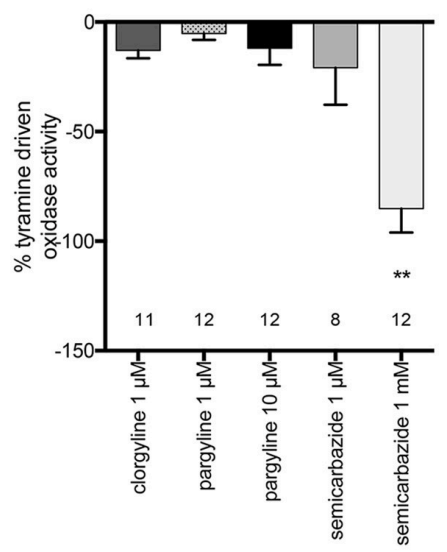

F

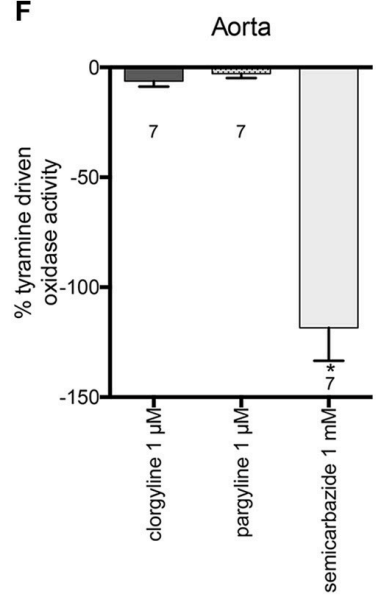

FIGURE 4 | SSAO mediates tyramine-driven amine oxidase activity in the MPVAT and its fractions, the AF and SVF, but not the MRV. Percent inhibition of tyramine driven oxidase activity by pharmacological inhibitors of MAO-A (1 $\mu \mathrm{M}$ clorgyline), MAO-B (1 $\mu \mathrm{M}$ pargyline), both MAO-A and MAO-B (10 $\mu \mathrm{M}$ pargyline) or SSAO (1 mM semicarbazide) in the (A) mesenteric resistance vessels (MRV), (B) mesenteric PVAT (MPVAT), (C) adipocyte fraction (AF), (D) stromal vascular fraction (SVF), and the positive controls (E) brain (positive control for MAO-A/B), and (F) aorta (positive control for SSAO). Bars represent the means \pm SEM for the number of animals indicated near each bar. Means were analyzed by a Kruskal-Wallis test followed by the Dunn's test for multiple comparisons. ${ }^{*} p<0.05$, ${ }^{* \star} p<0.01$,

${ }^{* * \star} p<0.001,{ }^{* \star \star *} p<0.0001$ vs. vehicle control (no inhibition).

secondary antibody (1:1000, MAO-A, MAO-B, COMT, VAP1) or LI-COR IRDye 700 secondary antibody $(1: 1000, \beta$-actin) in LI-COR Odyssey Blocking Buffer for $1 \mathrm{~h}$ at $4^{\circ} \mathrm{C}$, followed by washes with TBS-T for $10 \mathrm{~min}$ at $4^{\circ} \mathrm{C}$ (three times). Experiments using a competing peptide (MAO-B: cat\#SC-18401 P, VAP-1: SC-13741 P, Santa Cruz Biotechnology) were performed as above except for that before the primary antibody was added to the blot it was incubated overnight at $4^{\circ} \mathrm{C}$ with the competing peptide at $5 \mathrm{x}$ the concentration of the antibody. Bands were visualized using the LI-COR Odyssey Classic or the LI-COR Odyssey CLx. Densitometry was completed with Image J.

\section{Oxidase Activity Assay}

Samples were homogenized with the Bead Ruptor 24 (Omni International). The samples were centrifuged at $600 \times \mathrm{g}$ for $10 \mathrm{~min}$ and the supernatant transferred to new tubes. The protein concentration of an aliquot of the sample was measured before the oxidase assay using a Bicinchoninic Acid Protein Assay Kit (cat\# BCA1, Sigma-Aldrich) to inform us on the volume of the sample to load into the assay. MPVAT and the adipocyte fraction (AF) samples were loaded into a black clearbottom 96-well plate at $20 \mathrm{mg}$ of protein per well. Twice this protein, $40 \mathrm{mg}$, was loaded for the MRV, the SVF, brain (positive control for MAO) and aorta (positive control for SSAO). More protein was used for non-adipocyte containing tissues because the baseline $\mathrm{H}_{2} \mathrm{O}_{2}$ production in these extracts was less. Thus, more was loaded to ensure $\mathrm{H}_{2} \mathrm{O}_{2}$ would be detected. Samples in $1 \mathrm{X}$ reaction buffer were added into each well of a 96-well plate with an inhibitor of metabolism/or vehicle. The plate was incubated at room temperature for $30 \mathrm{~min}$. Then, the substrate was added (either tyramine or benzylamine; $1 \mathrm{mM}$ ), with 100 $\mu \mathrm{L}$ of the Amplex ${ }^{\circledR}$ Red Reagent to start the reaction. The plate was incubated for another $30 \mathrm{~min}$ at room temperature after which the fluorescence was read at 530-560 nm excitation and 


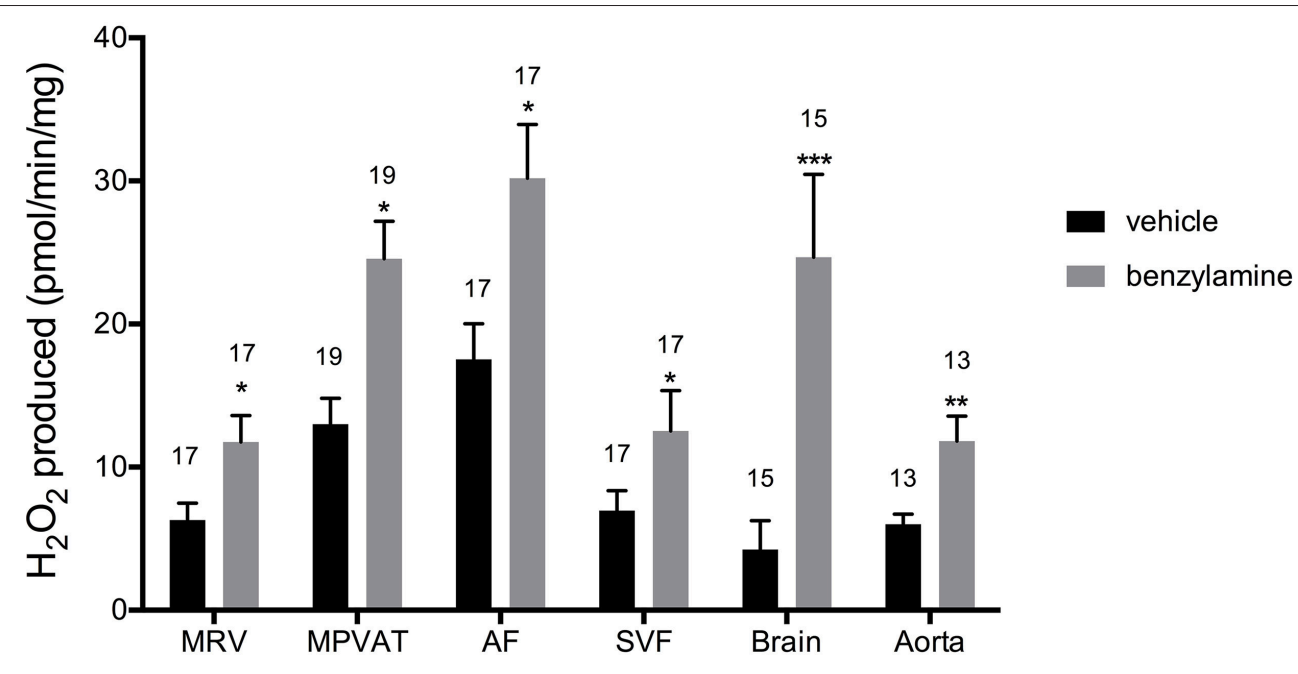

FIGURE 5 | Benzylamine drives amine oxidase activity in MRV, MPVAT, AF, and the SVF. MPVAT, mesenteric PVAT; AF, adipocyte fraction; MRV, mesenteric resistance vessels; SVF, stromal vascular fraction. The brain and aorta were also tested as positive controls. Bars represent the means \pm SEM for the number of animals indicated above each bar. Means were compared by a two-way ANOVA followed by a Mann-Whitney or a $t$-test. ${ }^{*} p<0.05$, ${ }^{\star *} p<0.01$, ${ }^{\star \star *} p<0.001$ vs. control of that same sample type.

$590 \mathrm{~nm}$ emission on the Infinite M1000 PRO (Tecan Group Ltd, Männedorf, Switzerland). Measures were compared to a resorufin standard curve and expressed as $\mathrm{pmol} / \mathrm{min} / \mathrm{mg}$ of protein.

\section{Isometric Contraction}

Rat third-order mesenteric resistance arteries cleaned of fat (-PVAT) or with fat intact (+PVAT) were mounted into a Multi Wire Myograph System 620M (Danish Myo Technology, Denmark). Data were acquired using a PowerLab Data Acquisitions unit (ADInstruments, Colorado Springs, CO, USA). Baths contained warmed, oxygenated PSS. Rings were pulled to optimum resting tension $(13.3 \mathrm{kpa})$ with the aid of the DMT Normalization Module for LabChart software and PowerLab (Danish Myo Technology and ADInstruments; http://cdn. adinstruments.com/adi-web/brochures/DMT-Normalization2011.pdf) and equilibrated for $1 \mathrm{~h}$ with washes every $20 \mathrm{~min}$. The arteries were exposed to an initial concentration of $60 \mathrm{mM}$ $\mathrm{KCl}$ to test viability. Tissues were washed and tone returned to baseline and exposed to another concentration of $60 \mathrm{mM} \mathrm{KCl}$ to elicit the maximum contraction. The $60 \mathrm{mM} \mathrm{KCl}$ maximum contraction was what we normalized the force of contraction to. Tissues were then washed and returned to baseline. Either vehicle or inhibitor was added for $1 \mathrm{~h}$ without washing. NE was then added in a cumulative fashion, with significant time necessary for a response to plateau prior to the next addition. If no response was recorded within $3 \mathrm{~min}$, the next concentration of NE was applied. Tissues were washed and a final $60 \mathrm{mM} \mathrm{KCl}$ addition was performed to test for tissue viability at the end of the experiment. Data were expressed as percent maximum contraction. The final contraction to $60 \mathrm{mM} \mathrm{KCl}$ was compared to the initial contraction (Data Supplementary Figures 4, 5). If the tissue did not contract to the final concentration of $60 \mathrm{mM}$ $\mathrm{KCl}$, the data for that experiment was not used.

\section{Statistical Analysis}

Data are reported as means \pm SEM for number of animals indicated by $\mathrm{N}$ or near each bar within the graphs. Statistical analyses were performed with GraphPad Prism 6.0 (GraphPad Software, Inc., La Jolla, CA). Outliers were identified and removed following a Grubb's test. Contraction was reported as means \pm SEM as a percentage of the initial contraction to 60 $\mathrm{mM} \mathrm{KCl}$. Potency means $\left(-\log \mathrm{EC}_{50}, \mathrm{M}\right)$ were calculated using GraphPad Prism 6.0. Where a maximum was not achieved, the values are estimated and true potencies equal or greater than that reported. $P<0.05$ was considered statistically significant.

\section{RESULTS}

\section{Aoc3 (the gene for SSAO) and Maoa (the gene for MAO-A) Are Highly Expressed in MPVAT}

MPVAT and the underlying artery-vein pair (Data Supplementary Figure 1) were dissected from male Sprague-Dawley rats and analyzed for the expression of amine metabolizing enzyme genes. Relative Maoa expression in the MPVAT was similar to that in the brain (Figure 1A), the positive control for Maoa and Maob (Jahng et al., 1997). However, MRV expression of Maoa was significantly lower than in the brain but not the MPVAT. Maob expression was significantly lower in both the MRV and in the MPVAT vs. the brain positive control (Figure 1B). When compared to the liver, a positive control for Comt expression (Karhunen et al., 1994), MRV and MPVAT had low levels of Comt expression (less than 0.01-relative expression from liver for both; data not shown). By contrast, Aoc3 (amine oxidase, copper containing 3 ; the gene for SSAO) was expressed at higher levels in the 


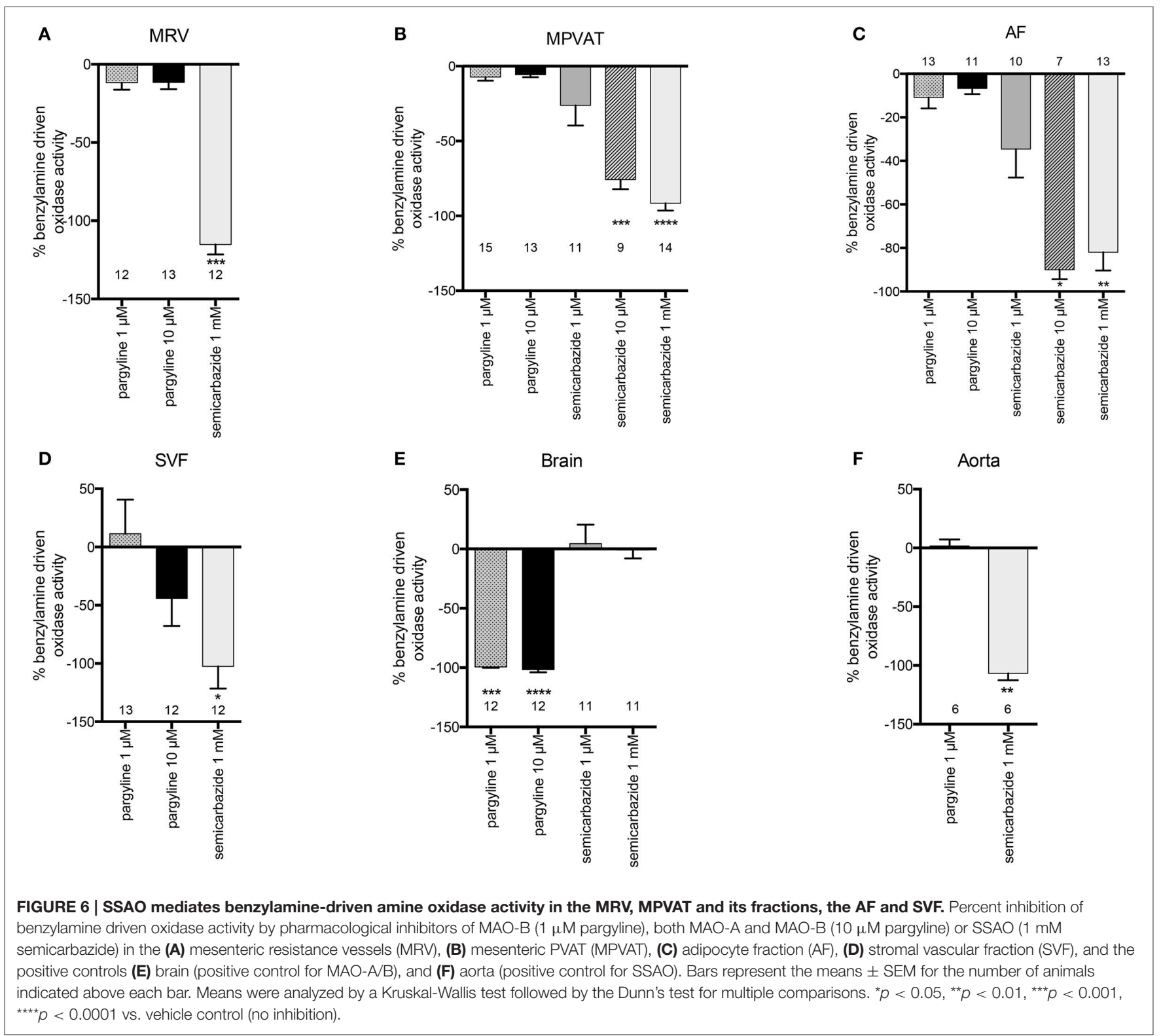

MPVAT (Figure 1C) vs. the MRV when compared relative to the aorta, a positive control for Aoc3 expression (Wanecq et al., 2006).

\section{MAO-A and SSAO Protein Is Present in MRV and MPVAT}

Western blot analysis of protein isolated from the MRV and associated MPVAT, revealed presence of MAO-A, MAO$\mathrm{B}$ and SSAO (Figure 2A). Consistent with there being no difference between the mRNA expression for Maoa in the MRV and MPVAT, there was no statistical difference in relative protein signal between the MRV and MPVAT $(p=0.29$; Figures 2A,B). MAO-B signal was lower the MPVAT than in the MRV (Figures 2A,C). Bands for COMT were not detected in either the MRV or the MPVAT (Figure 2A; densitometry not shown). SSAO signal was higher in the MPVAT vs. the MRV (Figures 2A,D), also consistent with Figure 1C.

\section{SSAO Mediates Tyramine and Benzylamine-Induced Amine Oxidase Activity in MPVAT}

Oxidation of amines in the MRV and in the MPVAT could alter vascular tone through the removal of vasoactive amines and through the release of the reaction product $\mathrm{H}_{2} \mathrm{O}_{2}$. To quantify the oxidase activity in these tissues, the MRV and MPVAT were carefully separated. MPVAT was split into its constituent fractions, the AF and the SVF. A microscopic image of the separated fractions is shown in Data Supplementary Figure 2, which represents the AF and SVF used in this study. Tyramine, a substrate for MAO-A, MAO-B and SSAO, was added to the 
sample extracts to drive oxidase activity. Addition of tyramine increased the oxidase activity $\left(\mathrm{H}_{2} \mathrm{O}_{2}\right.$ produced) in the MRV, MPVAT, the AF, and the SVF vs. vehicle $\left(\mathrm{H}_{2} \mathrm{O}\right)$ (Figure 3). The brain contains both MAO-A and B activity but low SSAO activity (Kalaria et al., 1988; Castillo et al., 1999). Thus, the brain served as a positive control for the MAOs. The brain had higher oxidase activity in response to tyramine vs. vehicle. The aorta, the positive control for SSAO, also had higher activity to tyramine vs. vehicle.

To determine which amine oxidase(s) contributed to the tyramine-driven $\mathrm{H}_{2} \mathrm{O}_{2}$ production in the mesentery, the MRV, MPVAT, AF and the SVF were incubated with inhibitors to each of the amine oxidases (MAO-A, MAO-B, and SSAO) before adding tyramine. Clorgyline, an irreversible inhibitor of MAO$\mathrm{A}$, was used due to its specificity to MAO-A ( $\mathrm{IC}_{50}$ of 0.03 $\mu \mathrm{M}$ and $8 \mu \mathrm{M}$ at MAO-B (Ozaita et al., 1997) and its lack of inhibition of SSAO (Clarke et al., 1982). Pargyline (1 $\mu \mathrm{M})$ was used to specifically inhibit MAO-B $\left(\mathrm{K}_{\mathrm{i}} 0.5 \mu \mathrm{M}\right)$ and a higher concentration $(10 \mu \mathrm{M})$ was used to inhibit both MAO$\mathrm{A}$ and $\mathrm{B}\left(\mathrm{K}_{\mathrm{i}}\right.$ for pargyline at MAO-A $=15 \mu \mathrm{M}$ Fowler et al., 1982). Semicarbazide was used to specifically inhibit SSAO, at a concentration $(1 \mathrm{mM})$ routinely used in monoamine assays to selectively inhibit SSAO activity ( $\mathrm{K}_{\mathrm{i}} 15 \mu \mathrm{M}$ Lizcano et al., 1996; Repessé et al., 2015). Oxidase activity was quantified as the amount of $\mathrm{H}_{2} \mathrm{O}_{2}$ produced per minute normalized to the amount of protein.

Tyramine-driven oxidase activity in the MRV was not reduced by the addition of clorgyline or pargyline (Figure 4A). However, there was a non-statistically significant reduction with $1 \mathrm{mM}$ semicarbazide (Figure 4A). On the other hand, semicarbazide significantly reduced (almost by 100\%) the tyramine-driven oxidase activity in the MPVAT and the AF (Figures 4B,C).

Oxidase activity in the SVF was not significantly reduced by inhibition of the MAOs or SSAO vs. vehicle (Figure 4D). However, each inhibitor (clorgyline, pargyline, and semicarbazide) caused large non-significant reductions in oxidase activity. No one enzyme had activity that was higher over the other enzymes. Thus, each amine oxidase (MAO-A, MAO-B, and SSAO) may contribute to oxidase activity in the SVF. The brain had reduced oxidase activity to clorgyline $(1 \mu \mathrm{M}$ - specific for MAO-A), pargyline (1 $\mu \mathrm{M}$ - specific for MAO and $10 \mu \mathrm{M}$ inhibits both MAO-A and MAO-B), but no reduction with the SSAO inhibitor semicarbazide (Figure 4E). Oxidase activity in the aorta was abolished by semicarbazide $(1 \mathrm{mM})$; by contrast, there was not reduction in oxidase activity by clorgyline $(1 \mu \mathrm{M})$ or pargyline $(1 \mu \mathrm{M})$ (Figure $4 \mathrm{~F})$. The results for these controls support that the assay can detect and distinguish between SSAO and MAO activity.

Benzylamine differs from tyramine in that it is a substrate for MAO-B and SSAO only (and not MAO-A). Addition of benzylamine increased oxidase activity vs. vehicle in the MPVAT, AF, SVF, brain, and aorta (Figure 5). Amine oxidase activity in the MRV was abolished by the SSAO inhibitor, semicarbazide, and was reduced in the MPVAT, AF, and the SVF (Figures 6A-D). This is different from what was observed with tyramine as the substrate, where the reduction with semicarbazide was not significant. Tyramine is a poor substrate for SSAO compared to benzylamine with a $\mathrm{K}_{\mathrm{m}}$ of $17.6 \mathrm{mM}$.
Whereas, the $K_{m}$ of benzylamine for SSAO is $161 \mu \mathrm{M}$ (Precious and Lyles, 1988). Some of the tyramine-driven oxidase activity in the MRV could have been due to other amine oxidases other than SSAO. Oxidase activity in the brain was completely abolished by inhibition of MAO-B with pargyline, but was not affected by inhibition of SSAO (Figure 6E). Oxidase activity in the aorta was not affected by pargyline, but was reduced significantly by semicarbazide (Figure 6F).

\section{NE Metabolism Contributes to the Anti-Contractile Effect of PVAT}

Third-order mesenteric resistance arteries with $(+)$ or without (-) PVAT were mounted on a 4-channel wire myograph. The force of contraction to $60 \mathrm{mM} \mathrm{KCl}$ of the arteries with and without PVAT were not different (Data Supplementary Figure 3). The arteries were incubated with either vehicle or an inhibitor prior to the generation of a NE concentration-response curve. The presence of PVAT gave a significant right-shift of the NE-response curve (Figure 7). NE had a $-\operatorname{logEC}{ }_{50}[\mathrm{M}]$ of $5.64 \pm 0.05$ in mesenteric resistance-PVAT and a $-\log \mathrm{EC}_{50}$ $[\mathrm{M}]$ of $5.08 \pm 0.06$ in arteries +PVAT (Figure 7). Inhibition of MAO-A and B by $10 \mu \mathrm{M}$ pargyline, or SSAO by semicarbazide $(1 \mathrm{mM})$ did not shift the NE concentration-response curve of arteries + or -PVAT vs. vehicle (Figures 8A,B). However, a leftshift of the +PVAT curve was observed with incubation with semicarbazide + pargyline $(10 \mu \mathrm{M}$; SP) suggesting that multiple NE metabolizers may contribute to PVAT's anti-contractile effect on mesenteric resistance arteries to NE (Figure 8C). To understand whether the shift in the NE-curve with SP was due to $\mathrm{H}_{2} \mathrm{O}_{2}$ being produced, we incubated +PVAT arteries with vehicle, SP, catalase $(2000 \mathrm{U} / \mathrm{ml})$, or SP + catalase $(2000 \mathrm{U} / \mathrm{ml})$ for $1 \mathrm{~h}$ prior to the addition of NE. The arteries that were incubated with SP and catalase had a left-shift in their responsecurve to NE vs. those incubated with catalase only (Figure 8D).

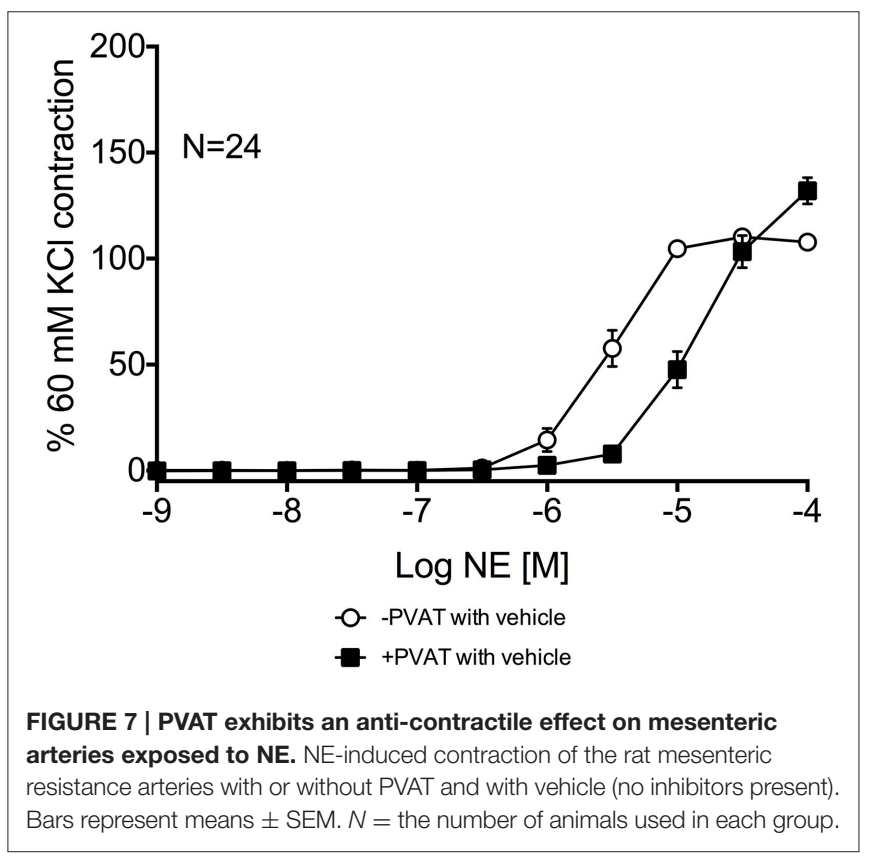


A

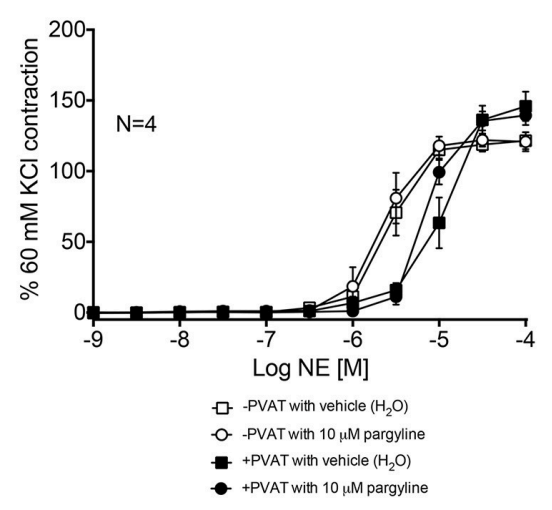

C

Semicarbazide \& pargyline

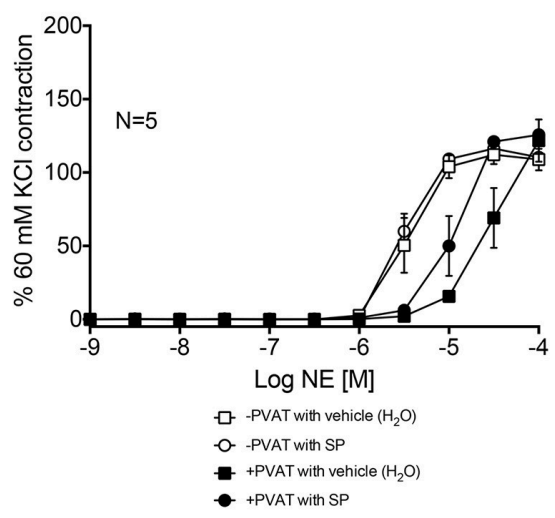

B Semicarbazide

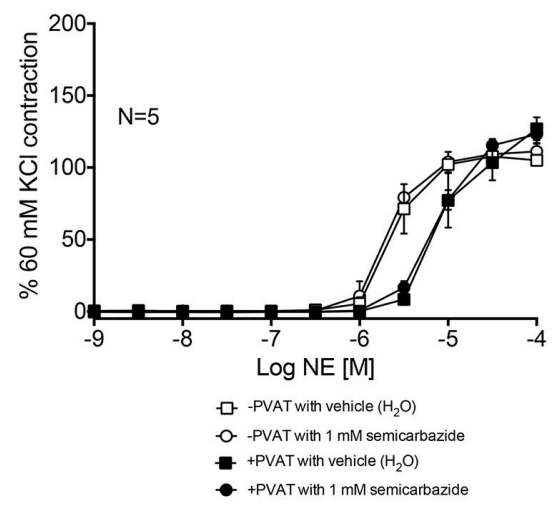

D

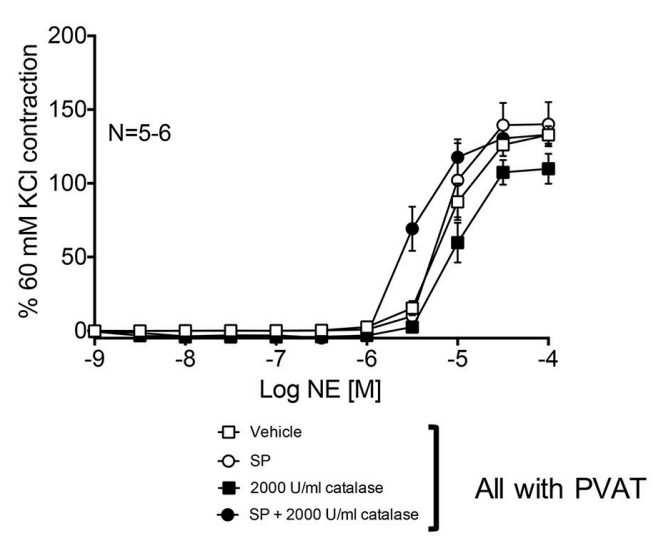

FIGURE 8 | Metabolism of $\mathrm{NE}$ and $\mathrm{H}_{2} \mathrm{O}_{2}$ release by PVAT inhibits contraction of rat mesenteric resistance arteries. NE-induced contraction of the rat mesenteric resistance arteries with or without PVAT and with or without (vehicle) the following inhibitors of NE metabolism. (A) pargyline (10 $\mu$ M; inhibits MAO-A and B), (B) semicarbazide (1 mM; inhibits SSAO), (C) SP = semicarbazide (1 mM) and pargyline (10 $\mu \mathrm{M}$ inhibits both MAO-A/B and SSAO). Arteries +PVAT were incubated with (D) SP and/or catalase (2000 U/ml). Force of contraction was normalized to the percent of the $60 \mathrm{mM} \mathrm{KCl}$ contraction. Bars represent means \pm SEM. $N=$ the number of animals used in each group.

However, no shift was observed in the arteries that were exposed to SP vs. vehicle suggesting that inhibition of metabolism alone is not always sufficient to affect arterial response to $\mathrm{NE}$ and that both PVAT's metabolism of NE and production of $\mathrm{H}_{2} \mathrm{O}_{2}$ are involved in decreasing contraction to NE. The pharmacological parameters for Figures 8B-D are listed in Table $\mathbf{1}$.

\section{NE Uptake Contributes to the Anti-Contractile Effect of PVAT}

Arteries incubated with the organic cation transporter 3 (OCT3) inhibitor corticosterone $(100 \mu \mathrm{M})$, had NE-response curves ( + and -PVAT) shifted to the left from vehicle (Figure 9A). However, the $-\log \mathrm{EC}_{50}$ of the two curves were not statistically different (Table 1). Nisoxetine $(1 \mu \mathrm{M})$, an inhibitor of the norepinephrine transporter (NET), shifted the NE-curve of +PVAT arteries significantly to the left vs. vehicle (Figure 9B; Table 1). We then tested whether transport of NE potentiated metabolism of NE in PVAT. Inhibition of SSAO [semicarbazide (1 mM)], MAO-A and B [pargyline $(10 \mu \mathrm{M})$ ], and OCT3 [corticosterone $(100 \mu \mathrm{M})$; SPC] did not alter PVAT's anticontractile effect when compared to vehicle (Figure 9C). The curve for the arteries +PVAT incubated with inhibitors was shifted slightly to the left from arteries +PVAT with vehicle but this shift was not significant (Table 1). It appears that inhibiting the entry of NE through OCT3 does not decrease NE removal. By contrast, inhibition of metabolism and uptake through NET by SPN $[\mathrm{SPN}=$ semicarbazide $(1 \mathrm{mM})$, pargyline $(10 \mu \mathrm{M})$, and nisoxetine $(1 \mu \mathrm{M})]$ shifted the +PVAT curve to the left (Figure 9D) reflected by an increase in potency of NE on + PVAT arteries (Table 1).

\section{DISCUSSION}

PVAT contains releasable catecholamines and a system for uptake of NE (Ayala-Lopez et al., 2014, 2015). However, a mechanism for metabolism for amines in PVAT has not been investigated. This study demonstrates that the amine oxidase SSAO is present and highly active in rat MPVAT and MPVAT adipocytes. We 
TABLE 1 | Pharmacological parameters of isolated mesenteric resistance arteries with (+) or without (-) PVAT.

\begin{tabular}{|c|c|c|c|}
\hline PVAT & Inhibitor & $-\operatorname{LogEC}_{50}(\mathrm{M})$ & $\begin{array}{c}\text { Max Contraction } \\
\% 60 \mathrm{mM} \mathrm{KCl}\end{array}$ \\
\hline - & Vehicle & $5.74 \pm 0.11$ & $121.51 \pm 5.98$ \\
\hline- & $10 \mu \mathrm{M}$ pargyline & $5.83 \pm 0.12$ & $120.82 \pm 6.73$ \\
\hline+ & Vehicle & $5.31 \pm 0.15$ & $145.90 \pm 10.40$ \\
\hline+ & $10 \mu \mathrm{M}$ pargyline & $5.40 \pm 0.15$ & $139.47 \pm 6.84$ \\
\hline- & Vehicle & $5.66 \pm 0.09$ & $105.03 \pm 3.57$ \\
\hline- & $1 \mathrm{mM}$ semicarbazide & $5.73 \pm 0.08$ & $111.17 \pm 5.42$ \\
\hline+ & Vehicle & $5.22 \pm 0.11$ & $126.92 \pm 8.00$ \\
\hline+ & $1 \mathrm{mM}$ semicarbazide & $5.29 \pm 0.09$ & $123.13 \pm 6.05$ \\
\hline - & Vehicle & $5.55 \pm 0.10$ & $108.83 \pm 7.34$ \\
\hline- & SP & $5.61 \pm 0.09$ & $110.35 \pm 3.20$ \\
\hline+ & Vehicle & $4.73 \pm 0.11$ & $121.78 \pm 14.43$ \\
\hline+ & $\mathrm{SP}$ & $5.13 \pm 0.11$ & $125.70 \pm 2.56$ \\
\hline+ & Vehicle & $5.36 \pm 0.11$ & $132.84 \pm 5.90$ \\
\hline+ & SP & $5.41 \pm 0.16$ & $142.81 \pm 15.39$ \\
\hline+ & $2000 \mathrm{U} / \mathrm{ml}$ catalase & $5.10 \pm 0.09$ & $113.06 \pm 9.12$ \\
\hline+ & $\mathrm{SP}+2000 \mathrm{U} / \mathrm{ml}$ catalase & $5.68 \pm 0.13^{a}$ & $136.49 \pm 8.37$ \\
\hline- & Vehicle & $5.72 \pm 0.12$ & $116.32 \pm 0.57$ \\
\hline- & $100 \mu \mathrm{M}$ corticosterone & $5.99 \pm 0.11$ & $113.98 \pm 9.26$ \\
\hline+ & Vehicle & $4.98 \pm 0.12$ & $132.78 \pm 18.89$ \\
\hline+ & $100 \mu \mathrm{M}$ corticosterone & $5.14 \pm 0.09$ & $107.38 \pm 3.39$ \\
\hline- & Vehicle & $5.71 \pm 0.10$ & $106.32 \pm 3.33$ \\
\hline- & $1 \mu \mathrm{M}$ nisoxetine & $5.80 \pm 0.10$ & $103.55 \pm 4.56$ \\
\hline+ & Vehicle & $5.23 \pm 0.15$ & $141.99 \pm 6.59$ \\
\hline+ & $1 \mu \mathrm{M}$ nisoxetine & $5.92 \pm 0.16^{\star}$ & $134.94 \pm 10.36$ \\
\hline- & Vehicle & $5.76 \pm 0.15$ & $131.05 \pm 8.60$ \\
\hline- & SPC & $5.46 \pm 0.12$ & $88.31 \pm 2.34 \#$ \\
\hline+ & Vehicle & $5.27 \pm 0.13$ & $130.02 \pm 6.19$ \\
\hline+ & SPC & $5.41 \pm 0.10$ & $108.17 \pm 3.63$ \\
\hline- & Vehicle & $5.57 \pm 0.11$ & $112.05 \pm 6.07$ \\
\hline- & SPN & $5.81 \pm 0.11$ & $114.56 \pm 3.15$ \\
\hline+ & Vehicle & $4.66 \pm 0.10$ & $114.91 \pm 3.44$ \\
\hline+ & SPN & $5.86 \pm 0.12^{\star \star \star}$ & $120.69 \pm 6.43$ \\
\hline
\end{tabular}

Points represent mean \pm SEM for values calculated from figures presented in Figures $\mathbf{8}$, 9. Unpaired Student's t-tests were performed to compare $-\log E C_{50}$ values between tissues with PVAT (+PVAT) and vehicle vs. +PVAT and inhibitor. Maximum contraction means were compared with a one-way ANOVA and a Holm's Sidak test for multiple comparisons. $S P C=$ pargyline $(10 \mu M)$, and corticosterone $(100 \mu M)$. SPN $=$ semicarbazide (1 mM), pargyline $(10 \mu \mathrm{M})$ and nisoxetine $(1 \mu \mathrm{M}) .{ }^{*} p<0.05,{ }^{* * *} p<0.001$ vs. +PVAT with vehicle response, \#p $<0.05$ vs. $-1+$ PVAT with vehicle, ${ }^{a} p<0.05$ vs. catalase $(2000 \mathrm{U} / \mathrm{ml})$.

also demonstrated that amine metabolism and NE uptake (which could assist in providing NE for metabolism intracellularly) contributes to the protective effect of PVAT.

Optimization of the Western protocol included the use of antibodies already validated or the validation of the antibodies. The MAO-A antibody was validated by our lab for its target specificity (Linder et al., 2008). The positive control bands on the Western blots for MAO-B were located by including a competing peptide in a validation experiment (Data Supplementary Figure 6). A Western blot was perform to select an appropriate positive control for COMT (Data Supplementary Figure 7). A competing peptide for the COMT antibody used was not commercially available. However, the Western data was consistent with low expression levels of mRNA detected. The appropriate band of interest for SSAO was located on the Western blot after including a competing peptide in a validation experiment (Data Supplementary Figure 8). Thus, we have confidence in the band identified by Western blot for SSAO.

Adipocytes in human abdominal and mammary white adipose tissue (WAT) contain both MAO-A and MAO-B (Pizzinat et al., 1999). Expression of mRNA and presence of protein for MAOA was found in MPVAT and the MRV. However, expression of $M a o b$ was low in MPVAT. There was higher expression of Aoc3 and SSAO in MPVAT vs. the MRV. SSAO is highly expressed in adipocytes and has several roles including adipogenesis (Mercier et al., 2001). In vascular smooth muscle cells, SSAO has roles in differentiation and the activation of glucose transport (El Hadri et al., 2002).

Pizzinat et al. (1999) suggested that the uptake-2 system (OCT3) in adipocytes would take up NE to be inactivated by MAO. We localized OCT3 to the PVAT adipocyte (Ayala-Lopez et al., 2015) and identified OCT3 as a mechanism for adipocytes to take up NE. Inhibition of NET also reduced NE uptake in MPVAT (Ayala-Lopez et al., 2015). Due to the presence of MAO$A$ and SSAO in MPVAT, we could expect metabolism of NE in PVAT to occur through transport-dependent and independent processes. If MAO-A is involved in the metabolism of amines in MPVAT, access to MAO would require an internalization of the amines from the extracellular environment and OCT3 and/or NET would be a way that NE can enter cells within MPVAT to be metabolized. SSAO is present on intracellular membranes (Enrique-Tarancón et al., 1998) and on the plasma membrane of adipocytes (Jalkanen and Salmi, 2001) where it is shed in a process that is regulated by TNF-alpha and insulin (Abella et al., 2004). Thus, entrance of catecholamines into adipocytes would not be required for SSAO action. However, inhibition of SSAO did not affect contraction of arteries to NE. Furthermore, inhibition of OCT3 and NE metabolism did not significantly shift the contractility curve but inhibiting NET alone or with SP shifted the curve of +PVAT arteries. Inactivation of NE by uptake through NET in MPVAT had the largest effect on contraction.

Stock and Westermann (1963) reported monoamine oxidase activity in rat epididymal adipose tissue. While, Bour et al. (2007) reported high MAO-A and SSAO activity in the AF from human subcutaneous adipose tissue. However, studies in PVAT had not been performed. We compared the amine oxidase activity from the MRV and the MPVAT to attain a whole picture of the oxidase activity in the vascular environment. SSAO was the predominant oxidase enzyme active in MPVAT. Surprisingly, we did not detect MAO-A activity in MPVAT although MAO-A protein and mRNA were present. The high SSAO activity could have masked lower monoamine oxidase activity and the MAO-A 


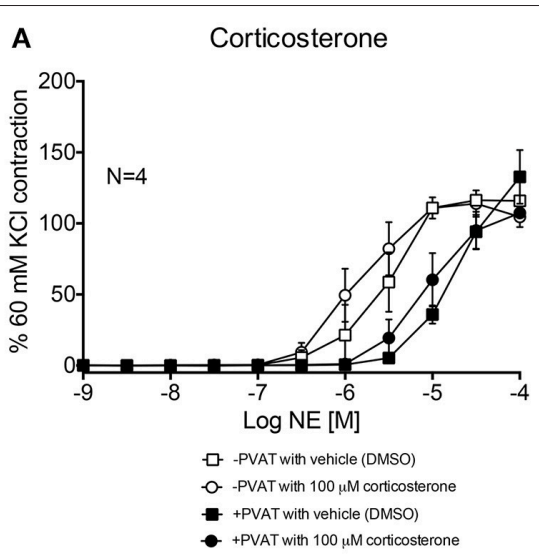

C Semicarbazide, pargyline, and corticosterone

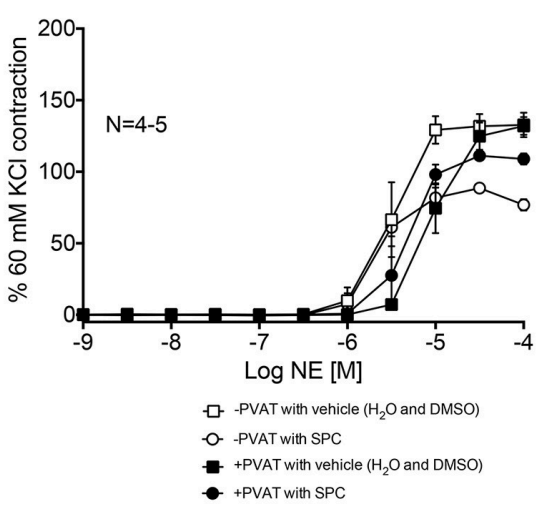

B

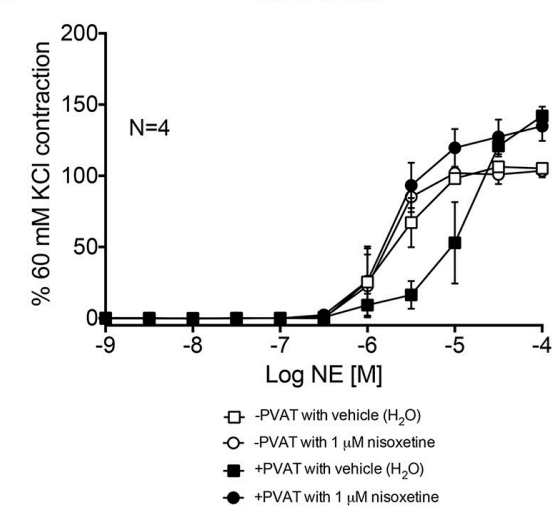

D

Semicarbazide, pargyline, and nisoxetine

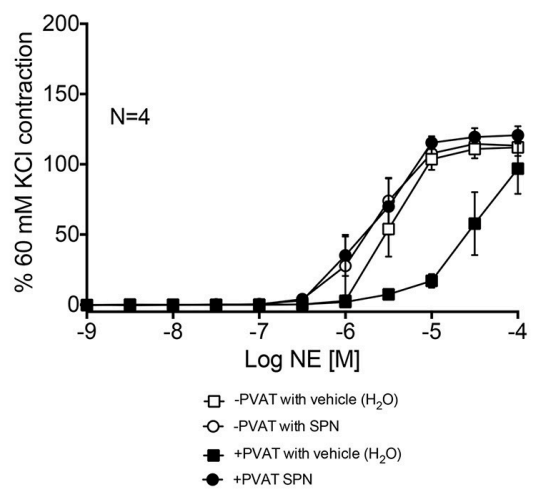

FIGURE 9 | NE-induced contraction of mesenteric resistance arteries with and without PVAT incubated with NE uptake inhibitors. (A) NE-induced contraction of the rat mesenteric resistance arteries + or -PVAT, with corticosterone (100 $\mu \mathrm{M}$; inhibits OCT3) or vehicle $\left(\mathrm{H}_{2} \mathrm{O}\right)$. (B) NE-induced contraction of the rat mesenteric resistance arteries + or -PVAT, incubated with nisoxetine ( $1 \mu \mathrm{M}$; inhibits NET) or vehicle $\left(\mathrm{H}_{2} \mathrm{O}\right)$. (C) SPC = semicarbazide (1 mM), pargyline (10 $\left.\mu \mathrm{M}\right)$, and corticosterone (100 $\mu \mathrm{M}$; used to inhibit SSAO, MAO-A/B and OCT3), and (D) SPN = semicarbazide (1 mM), pargyline (10 $\mu \mathrm{M})$ and nisoxetine (1 $\mu \mathrm{M}$; used to inhibit SSAO, MAO-A/B, and NET). The force of contraction was normalized to the percent of the $60 \mathrm{mM} \mathrm{KCl}$ contraction. Bars represent means $\pm \mathrm{SEM}$. $\mathrm{N}=$ the number of animals used in each group.

activity fell below our level of detection. The inclusion of the brain and aorta as controls assured us that the assay could detect and distinguish MAO and SSAO activity.

One limitation is that the substrates used in the oxidase activity assay, tyramine and benzylamine, are not the likely endogenous substrates for amine oxidases in PVAT. They were used as they are well characterized substrates for MAO and SSAO letting us come to more accurate conclusions as to which enzymes are active. Candidates for endogenous substrates for SSAO include aminoacetone, methylamine, 5-HT, and NE Lyles, 1995. Both NE and 5-HT are substrates of SSAO in rat brown adipose tissue (Barrand and Callingham, 1982). Unfortunately, NE could not be used in the oxidase assay because of its quick oxidization by the reagent in the Amplex Red assay (Elliott et al., 1989b; Zhao et al., 2012). The detection of NE metabolites after interaction with SSAO could assist in answering the question of whether NE is a substrate for SSAO in MPVAT. However, we did not perform these experiments as this assay is still in the development phase. Observed amine oxidase activities to NE and other prototypical substrates may be different when compared across species and adipose depots.

Another possibility is that degradation of amines by oxidation occurred by other enzymes not tested, especially in the MRV and the SVF where we were less successful at inhibiting the oxidase activity with the specific inhibitors used. For example, ceruloplasmin, an adipokine that is increased in the adipose tissue of obese humans (Arner et al., 2014), has broad specificity for degrading amines including NE, epinephrine, dihydroxyphenylalanine (DOPA), and 5-HT (Gutteridge and Stocks, 1981).

Due to the closeness of artery and vein in the mesenteric third order branches and the resulting inability to ascribe PVAT as belonging to either the artery and vein, both the artery and vein pair were used in the oxidase assays. The PVAT envelops both artery and vein, which are positioned close together and without a clear delineation of PVAT between the two. Thus, to gain an appreciation of the total tissue amine oxidases within the vascular environment we have kept the artery and vein together and used 


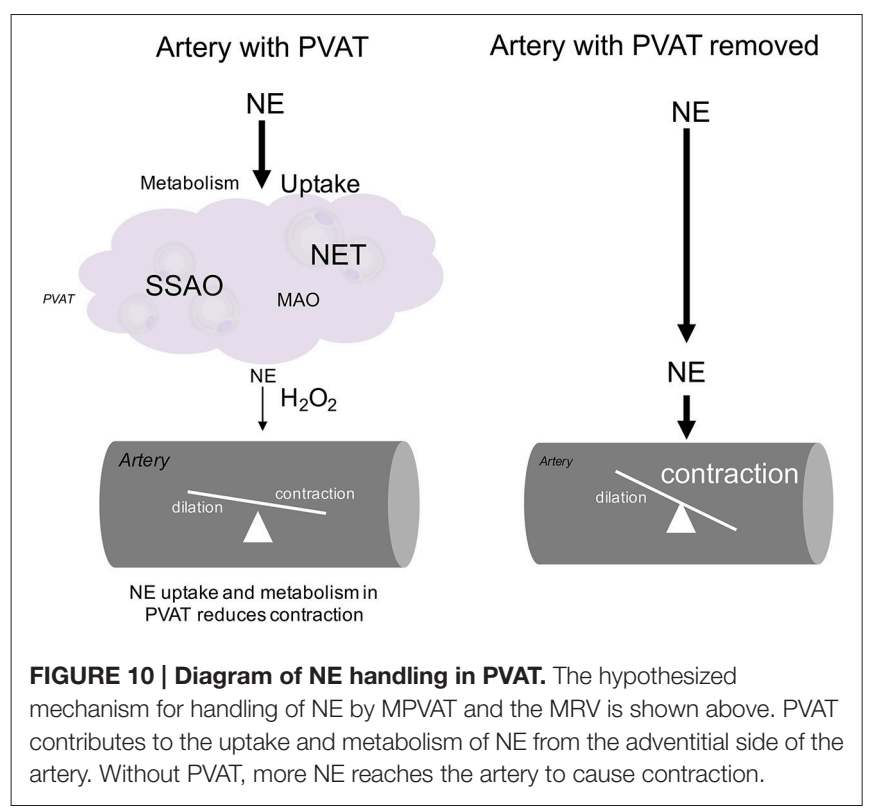

all of the PVAT that surrounds them for the Westerns and oxidase activity assays. In contractility, we have only used the artery since there is a larger literature base regarding PVAT's effect on arteries. However, more studies are needed to understand PVAT's effect on veins. Our group is highly interested in the veins of the splanchnic region and their role in peripheral resistance (Johnson et al., 2002; Ni et al., 2008; Watts et al., 2015; Seitz et al., 2016). Thus, PVAT's effect on veins is an avenue of future research.

Amine metabolism in rat mesenteric arteries has been found to occur mostly through SSAO, with less involvement from MAO-A (Elliott et al., 1989a). Elliott et al. (1989c) observed that inhibiting MAO or SSAO (with clorgyline or MDL 72145, respectively) did not shift the tyramine response curve of rat mesenteric arteries (without PVAT). However, a shift was achieved upon blocking both MAO and SSAO. In our studies, MAO and SSAO inhibition did not shift the NE-induced contraction in arteries -PVAT. By contrast, arteries +PVAT demonstrated a left-shift to NE when MAO, SSAO, and $\mathrm{H}_{2} \mathrm{O}_{2}$ were inhibited, supporting a redundant system for inactivating vasoactive amines that produces $\mathrm{H}_{2} \mathrm{O}_{2} . \mathrm{H}_{2} \mathrm{O}_{2}$ limits endothelial $\mathrm{NO}$ formation and reduces endothelium-dependent relaxation of the rat aorta (Sturza et al., 2013). In contrast, metabolism of 5$\mathrm{HT}$ by MAO in the rat basilar artery was shown to lead to $\mathrm{H}_{2} \mathrm{O}_{2}$ generation, which by inhibiting the opening of $\mathrm{BK}_{\mathrm{Ca} 2+}$ channels, potentiated contraction (Poon et al., 2010). Our study supported that released $\mathrm{H}_{2} \mathrm{O}_{2}$ upon $\mathrm{NE}$ metabolism was contributing to the PVAT's anti-contractile effect.

Our proposed hypothesis is illustrated in Figure 10. On the left, an artery with PVAT is exposed to NE. The NE is taken up through NET and subsequently is metabolized in the PVAT either through SSAO or MAO. A small amount of NE reaches the artery relative to the amount of NE originally released along with $\mathrm{H}_{2} \mathrm{O}_{2}$ and less contraction of the artery occurs. On the right, an artery with the PVAT removed is exposed to NE. The full amount of NE reaches the artery to cause contraction. A small amount of NE (not enough to affect contraction) may be metabolized within the artery.

We can place our findings in context of the disease that brought us to examine amine metabolism in PVAT. SSAO activity in MPVAT could influence vascular inflammation as it has a role in inflammation and is being explored as a biomarker for atherosclerosis (Mészáros et al., 1999; Karadi et al., 2002). In obesity, SSAO and MAO activity near the vessel could promote vascular remodeling. We do not have data to support this. Thus, investigation into SSAO and MAO activity in PVAT during obesity in necessary.

\section{CONCLUSIONS}

The MRV and MPVAT with its corresponding AF and SVF contain amine oxidase activity mostly attributed to SSAO. Amine metabolism and NE uptake in PVAT protects arteries from contraction to NE. Studies are necessary to understand how this NE handling system functions in human PVAT and how it may be altered in obesity.

\section{AUTHOR CONTRIBUTIONS}

NA: Conceived the study, designed and executed the experiments, analyzed and interpreted the data, wrote and revised the manuscript. JT: Performed the Western blots and assisted in writing the methods for the Western experiments, read and revised the manuscript. SW: Conceived the study, guided the experimental design, data analysis and interpretation, read and revised the manuscript.

\section{FUNDING}

This work was funded by NIH NHLBI P01HL70687 and F31 HL128035.

\section{ACKNOWLEDGMENTS}

We would like to acknowledge Emma Darios for her excellent technical assistance.

\section{SUPPLEMENTARY MATERIAL}

The Supplementary Material for this article can be found online at: http://journal.frontiersin.org/article/10.3389/fphys. 2017.00037/full\#supplementary-material

Data Supplementary Figure 1 | Image representing the rat mesenteric vessels and PVAT used in this study. The location of the mesenteric resistance artery-vein pair used is indicated by the red arrow and their associated MPVAT is indicated by the white arrow.

Data Supplementary Figure 2 | Image representing the AF and the SVF isolated from whole MPVAT. Representative of the following experiments where the AF (left) and SVF (right) were used. Phase contrast images were taken with a $20 \times$ objective. The black scale bar $=100 \mu \mathrm{M}$.

Data Supplementary Figure 3 | Comparison of the force of contraction between the +PVAT and -PVAT mesenteric resistance arteries. Arteries 
were exposed to $60 \mathrm{mM} \mathrm{KCl}$ at the beginning of each experiment. Graphed are the "initial" force of contraction of the arteries + and -PVAT from the experiments shown in Figures 8, 9. Data were compared with a paired $t$-test and shown to be non-significant $(p=0.20)$. Bars represent means \pm SEM. $N$, the number of animals used in each group. NS, non-significant $(p>0.05)$.

\section{Data Supplementary Figure 4 | Comparison of the force of contraction between the +PVAT and -PVAT mesenteric resistance arteries at the initial part of the experiment vs. the end of experiment. Arteries were} exposed to $60 \mathrm{mM} \mathrm{KCl}$ at the beginning of each experiment and at the end. Graphed are the "initial" vs. the "end" forces of contraction of the arteries + and -PVAT from Figure 8. Data were compared with a 2-way ANOVA and shown to be non-significant. Bars represent means \pm SEM. $N$, the number of animals used in each group.

\section{Data Supplementary Figure 5 | Comparison of the force of contraction between the +PVAT and -PVAT mesenteric resistance arteries at the initial part of the experiment vs. the end of experiment. Arteries were} exposed to $60 \mathrm{mM} \mathrm{KCl}$ at the beginning of each experiment and at the end. Graphed are the "initial" vs. the "end" forces of contraction of the arteries + and -PVAT from Figure 9. Data were compared with a 2-way ANOVA. Bars represent means \pm SEM. $N$, the number of animals used in each group. ${ }^{*} p<0.05$.

\section{Data Supplementary Figure 6 | MAO-B Western blot optimization} experiment. Western blots for MAO-B were prepared that were exposed to anti-MAO-B antibody (no peptide; left) or the antibody and the competing peptide (right) to locate the band for MAO-B and select the appropriate positive control tissue. MAO-B signal was observed at around $45 \mathrm{kDa}$. The stomach fundus gave the least non-specific signal and thus was selected as the positive control.

\section{Data Supplementary Figure 7 | COMT Western blot optimization} experiment. Western blots for COMT were prepared to select the proper positive control tissue. COMT signal was observed at around $45 \mathrm{kDa}$. The competing peptide was not commercially available. The Jurkat whole cell lysate gave the least non-specific signal and thus was selected as the positive control.

\section{Data Supplementary Figure 8 | VAP-1 (SSAO) Western blot optimization} experiment. Western blots for VAP-1 (SSAO) were prepared that were exposed to anti-VAP-1 antibody (no peptide; left) or the antibody and the competing peptide (right) to locate the band for VAP-1. VAP-1 signal was observed at around $80 \mathrm{kDa}$. The lung was the positive control in this experiment. However, because the signal was not strong, the aorta was used as the positive control in subsequent experiments.

\section{REFERENCES}

Abella, A., Garcia-Vicente, S., Viguerie, N., Ros-Baro, A., Camps, M., Palacin, M., et al. (2004). Adipocytes release a soluble form of VAP-1/SSAO by a metalloprotease-dependent process and in a regulated manner. Diabetologia 47, 429-438. doi: 10.1007/s00125-004-1346-2

Arner, E., Forrest, A. R. R., Ehrlund, A., Mejhert, N., Itoh, M., Kawaji, H., et al. (2014). Ceruloplasmin is a novel adipokine which is overexpressed in adipose tissue of obese subjects and in obesity-associated cancer cells. PLoS ONE 9:e80274. doi: 10.1371/journal.pone.0080274

Ayala-Lopez, N., Jackson, W. F., Burnett, R., Wilson, J. N., Thompson, J. M., and Watts, S. W. (2015). Organic cation transporter 3 contributes to norepinephrine uptake into perivascular adipose tissue. Am. J. Physiol. Heart Circ. Physiol. 309, H1904-H1914. doi: 10.1152/ajpheart. 00308.2015

Ayala-Lopez, N., Martini, M., Jackson, W., F., Darios, E., Burnett, R., Seitz, B., et al. (2014). Perivascular adipose tissue contains functional catecholamines. Pharmacol. Res. Perspect. 2:e00041. doi: 10.1002/prp2.41

Barrand, M. A., and Callingham, B. A. (1982). Monoamine oxidase activities in brown adipose tissue of the rat: some properties and subcellular distribution. Biochem. Pharmacol. 31, 2177-2184. doi: 10.1016/0006-2952(82)90511-1

Belfrage, E., Fredholm, B. B., and Rosell, S. (1977). Effect of Catechol-O-MethylTransferase (COMT) inhibition on the vascular and metabolic responses to noradrenaline, isoprenaline and sympathetic nerve stimulation in canine subcutaneous adipose tissue. Naunyn-Schmiedeberg's Arch. Pharmacol. 300, 11-17. doi: 10.1007/BF00505074

Bour, S., Daviaud, D., Gres, S., Lefort, C., Prévot, D., Zorzano, A., et al. (2007). Adipogenesis-related increase of semicarbazide-sensitive amine oxidase and monoamine oxidase in human adipocytes. Biochimie 89, 916-925. doi: 10.1016/j.biochi.2007.02.013

Brandes, R. P. (2007). The fatter the better? Perivascular adipose tissue attenuates vascular contraction through different mechanisms. Br. J. Pharmacol. 151, 303-304. doi: 10.1038/sj.bjp.0707229

Castillo, V., Lizcano, J. M., and Unzeta, M. (1999). Presence of SSAO in human and bovine meninges and microvessels. Neurobiology (Bp). 7, 263-272.

Chaldakov, G. N., Tonchev, A. B., Stankulov, I. S., Ghenev, P. I., Fiore, M., Aloe, L., et al. (2007). Periadventitial adipose tissue (Tunica Adiposa): enemy or friend around?. Arch. Pathol. Lab. Med. 131, 1766-1777. doi: 10.1043/1543-2165(2007)131[1766a:PATTAE]2.0.CO;2

Clarke, D. E., Lyles, G. A., and Callingham, B. A. (1982). A comparison of cardiac and vascular clorgyline-resistant amine oxidase and monoamine oxidase: inhibition by amphetamine, mexiletine and other drugs. Biochem. Pharmacol. 31, 27-35. doi: 10.1016/0006-2952(82)90231-3

El Hadri, K., Moldes, M., Mercier, N., Andreani, M., Pairault, J., and Feve, B. (2002). Semicarbazide-sensitive amine oxidase in vascular smooth muscle cells: differentiation-dependent expression and role in glucose uptake. Arterioscler. Thromb. Vasc. Biol. 22, 89-94. doi: 10.1161/hq0102.101550

Elliott, J., Callingham, B. A., and Sharman, D. F. (1989a). Semicarbazide-Sensitive Amine Oxidase (SSAO) of the rat aorta. interactions with some naturally occurring amines and their structural analogues. Biochem. Pharmacol. 38, 1507-1515. doi: 10.1016/0006-2952(89)90191-3

Elliott, J., Callingham, B. A., and Sharman, D. F. (1989b). Metabolism of amines in the isolated perfused mesenteric arterial bed of the rat. Br. J. Pharmacol. 98, 507-514. doi: 10.1111/j.1476-5381.1989.tb12624.x

Elliott, J., Callingham, B. A., and Sharman, D. F. (1989c). The influence of amine metabolizing enzymes on the pharmacology of tyramine in the isolated perfused mesenteric arterial bed of the rat. Br. J. Pharmacol. 98, 515-522. doi: 10.1111/j.1476-5381.1989.tb12625.x

Enrique-Tarancón, G., Marti, L., Morin, N., Lizcano, J. M., Unzeta, M., Sevilla, L., et al. (1998). Role of semicarbazide-sensitive amine oxidase on glucose transport and glut4 recruitment to the cell surface in adipose cells. J. Biol. Chem. 273, 8025-8032.

Fesus, G., Dubrovska, G., Gorzelniak, K., Kluge, R., Huang, Y., Luft, F. C., et al. (2007). Adiponectin is a novel humoral vasodilator. Cardiovasc. Res. 75, 719-727. doi: 10.1016/j.cardiores.2007.05.025

Fowler, C. J., Mantle, T. J., and Tipton, K. F. (1982). The nature of the inhibition of rat liver monoamine oxidase types $\mathrm{A}$ and $\mathrm{B}$ by the acetylenic inhibitors clorgyline, L-deprenyl and pargyline. Biochem. Pharmacol. 31, 3555-3561. doi: 10.1016/0006-2952(82)90575-5

Gao, Y. J., Takemori, K., Su, L. Y., An, W. S., Lu, C., Sharma, A. M., et al. (2006). Perivascular adipose tissue promotes vasoconstriction: the role of superoxide anion. Cardiovasc. Res. 71, 363-373. doi: 10.1016/j.cardiores.2006.03.013

Gutteridge, J. M., and Stocks, J. (1981). Caeruloplasmin: physiological and pathological perspectives. Crit. Rev. Clin. Lab. Sci. 14, 257-329. doi: $10.3109 / 10408368109105866$

Hall, J. E., da Silva, A. A., do Carmo, J. M., Dubinion, J., Hamza, S., Munusamy, S., et al. (2010). Obesity-induced hypertension: role of sympathetic nervous system, leptin, and melanocortins. J. Biol. Chem. 285, 17271-17276. doi: 10.1074/jbc.R110.113175

Intengan, H. D., and Schiffrin, E. L. (2000). Structure and mechanical properties of resistance arteries in hypertension: role of adhesion molecules and extracellular matrix determinants. Hypertension 36, 312-318. doi: 10.1161/01.HYP.36.3.312

Jahng, J. W., Houpt, T. A., Wessel, T. C., Chen, K., Shih, J. C., and Joh, T. H. (1997). Localization of monoamine oxidase A and B mRNA in the rat brain by in situ hybridization. Synapse 25, 30-36. doi: 10.1002/(SICI)1098-2396(199701)25:1<30::AID-SYN4>3.0.CO;2-G 
Jalkanen, S., and Salmi, M. (2001). Cell surface monoamine oxidases: enzymes in search of a function. EMBO J. 20, 3893-3901. doi: 10.1093/emboj/20.15.3893

Johnson, R. J., Fink, G. D., Watts, S. W., and Galligan, J. J. (2002). Endothelin receptor function in mesenteric veins from deoxycorticosterone acetate salt-hypertensive rats. J. Hypertens. 20, 665-676. doi: 10.1097/00004872-200204000-00024

Kalaria, R. N., Mitchell, M. J., and Harik, S. I. (1988). Monoamine oxidases of the human brain and liver. Brain 111, 1441-1451. doi: 10.1093/brain/111.6.1441

Karadi, I., Meszaros, Z., Csanyi, A., Szombathy, T., Hosszufalusi, N., Romics, L., et al. (2002). Serum Semicarbazide-Sensitive Amine Oxidase (SSAO) activity is an independent marker of carotid atherosclerosis. Clin. Chim. Acta 323, 139-146. doi: 10.1016/S0009-8981(02)00189-4

Karhunen, T., Tilgmann, C., Ulmanen, I., Julkunen, I., and Panula, P. (1994). Distribution of catechol-o-methyltransferase enzyme in rat tissues. J. Histochem. Cytochem. 42, 1079-1090. doi: 10.1177/42.8.8027527

Kotchen, T. A. (2010). Obesity-related hypertension: epidemiology, pathophysiology, and clinical management. Am. J. Hypertens. 23, 1170-1178. doi: 10.1038/ajh.2010.172

Linder, A. E., Ni, W., Szasz, T., Burnett, R., Diaz, J., Geddes, T. J., et al. (2008). A serotonergic system in veins: serotonin transporter-independent uptake. $J$. Pharmacol. Exp. Ther. 325, 714-722. doi: 10.1124/jpet.107.135699

Livak, K. J., and Schmittgen, T. D. (2001). Analysis of relative gene expression data using real-time quantitative PCR and the $2^{-\Delta \Delta C T}$ method. Methods 25 , 402-408. doi: 10.1006/meth.2001.1262

Lizcano, J. M., Fernandez de Arriba, A., Tipton, K. F., and Unzeta, M. (1996). Inhibition of bovine lung Semicarbazide-Sensitive Amine Oxidase (SSAO) by some hydrazine derivatives. Biochem. Pharmacol. 52, 187-195. doi: 10.1016/0006-2952(96)00132-3

Löhn, M., Dubrovska, G., Lauterbach, B., Luft, F. C., Gollasch, M., and Sharma, A. M. (2002). Periadventitial fat releases a vascular relaxing factor. FASEB J. 16, 1057-1063. doi: 10.1096/fj.02-0024com

Lyles, G. A. (1995). Substrate-specificity of mammalian tissue-bound semicarbazide-sensitive amine oxidase. Prog. Brain. Res. 106, 293-303. doi: 10.1016/S0079-6123(08)61226-1

Mercier, N., Moldes, M., El Hadri, K., and Fève, B. (2001). Semicarbazidesensitive amine oxidase activation promotes adipose conversion of 3T3-L1 cells. Biochem. J. 358(Pt 2), 335-342. doi: 10.1042/bj3580335

Mészáros, Z., Karádi, I., Csányi, A., Szombathy, T., Romics, L., and Magyar, K. (1999). Determination of human serum semicarbazide-sensitive amine oxidase activity: a possible clinical marker of atherosclerosis. Eur. J. Drug Metab. Pharmacokinet. 24, 299-302. doi: 10.1007/BF03190036

Ni, W., Geddes, T. J., Priestley, J. R., Szasz, T., Kuhn, D. M., and Watts, S. W. (2008). The existence of a local 5-hydroxytryptaminergic system in peripheral arteries. Br. J. Pharmacol. 154, 663-674. doi: 10.1038/bjp.2008.111

Ozaita, A., Olmos, G., Boronat, M. A., Lizcano, J. M., Unzeta, M., and GarcíaSevilla, J. A. (1997). Inhibition of monoamine oxidase A and B activities by imidazol(ine)/guanidine drugs, nature of the interaction and distinction from I2-imidazoline receptors in rat liver. $\mathrm{Br}$. J. Pharmacol. 121, 901-912. doi: 10.1038/sj.bjp.0701214

Pizzinat, N., Marti, L., Remaury, A., Leger, F., Langin, D., Lafontan, M., et al. (1999). High expression of monoamine oxidases in human white adipose tissue: evidence for their involvement in noradrenaline clearance. Biochem. Pharmacol. 58, 1735-1742. doi: 10.1016/S0006-2952(99)00270-1

Poon, C. C. W., Seto, S. W., Au, A. L. S., Zhang, Q., Li, R. W. S., Lee, W. Y. W., et al. (2010). Mitochondrial monoamine oxidase-a-mediated hydrogen peroxide generation enhances 5-hydroxytryptamine-induced contraction of rat basilar artery. Br. J. Pharmacol. 161, 1086-1098. doi: 10.1111/j.1476-5381.2010.00941.x

Precious, E., and Lyles, G. A. (1988). Properties of a semicarbazide-sensitive amine oxidase in human umbilical artery. J. Pharm. Pharmacol. 40, 627-633.

Repessé, X., Moldes, M., Muscat, A., Vatier, C., Chetrite, G., Gille, T., et al. (2015). Hypoxia inhibits semicarbazide-sensitive amine oxidase activity in adipocytes. Mol. Cell. Endocrinol. 411, 58-66. doi: 10.1016/j.mce.2015.04.011

Seitz, B. M., Krieger-Burke, T., Fink, G. D., and Watts, S. W. (2016). Serial measurements of splanchnic vein diameters in rats using high-frequency ultrasound. Front. Pharmacol. 7:116. doi: 10.3389/fphar.2016.00116

Soltis, E. E., and Cassis, L. A. (1991). Influence of perivascular adipose tissue on rat aortic smooth muscle responsiveness. Clin. Exp. Hypertens. A. 13, 277-296. doi: 10.3109/10641969109042063

Stock, K., and Westermann, E. O. (1963). Concentration of norepinephrine, serotonin, and histamine, and of amine-metabolizing enzymes. J. Lipid Res. 4, 297-304.

Sturza, A., Leisegang, M. S., Babelova, A., Schroder, K., Benkhoff, S., Loot, A. E., et al. (2013). Monoamine oxidases are mediators of endothelial dysfunction in the mouse aorta. Hypertension 62, 140-146. doi: 10.1161/HYPERTENSIONAHA.113.01314

Szasz, T., Bomfim, G. F., and Webb, R. C. (2013). The influence of perivascular adipose tissue on vascular homeostasis. Vasc. Health Risk Manag. 9, 105-116. doi: 10.2147/VHRM.S33760

Vargovic, P., Ukropec, J., Laukova, M., Kurdiova, T., Balaz, M., Manz, B., et al. (2013). Repeated immobilization stress induces catecholamine production in rat mesenteric adipocytes. Stress 16, 340-352. doi: 10.3109/10253890.2012.736046

Visentin, V., Boucher, J., Bour, S., Prevot, D., Castan, I., Carpene, C., et al. (2005). Influence of high-fat diet on amine oxidase activity in white adipose tissue of mice prone or resistant to diet-induced obesity. J. Physiol. Biochem. 61, 343-352. doi: 10.1007/BF03167051

Wanecq, E., Bour, S., Verwaerde, P., Smih, F., Valet, P., and Carpéné, C. (2006). Increased monoamine oxidase and semicarbazide-sensitive amine oxidase activities in white adipose tissue of obese dogs fed a high-fat diet. J. Physiol. Biochem. 62, 113-123. doi: 10.1007/BF031 74072

Watts, S. W., Darios, E. S., Seitz, B. M., and Thompson, J. M. (2015). 5-HT is a potent relaxant in rat superior mesenteric veins. Pharmacol. Res. Perspect. 3:e00103. doi: 10.1002/prp2.103

Zhao, B., Summers, F. A., and Mason, R. P. (2012). Photooxidation of amplex red to resorufin: implications of exposing the amplex red assay to light. Free Radic. Biol. Med. 53, 1080-1087. doi: 10.1016/j.freeradbiomed.2012. 06.034

Conflict of Interest Statement: The authors declare that the research was conducted in the absence of any commercial or financial relationships that could be construed as a potential conflict of interest.

Copyright (C) 2017 Ayala-Lopez, Thompson and Watts. This is an open-access article distributed under the terms of the Creative Commons Attribution License (CC BY). The use, distribution or reproduction in other forums is permitted, provided the original author(s) or licensor are credited and that the original publication in this journal is cited, in accordance with accepted academic practice. No use, distribution or reproduction is permitted which does not comply with these terms. 